\title{
Far-field tsunami threat in the north Atlantic basin from large scale flank collapses of the Cumbre Vieja volcano, La Palma
}

\author{
Babak Tehranirad ${ }^{1}$, Jeffrey C. Harris ${ }^{2 \dagger}$, Annette R. Grilli ${ }^{2}$, Stephan \\ T. Grilli ${ }^{2}$, Stéphane Abadie ${ }^{3}$, James T. Kirby ${ }^{1}$ and Fengyan Shi ${ }^{1}$ \\ 1. Center for Applied Coastal Research, Dept. of Civil and Environmental Eng., \\ University of Delaware, Newark, DE 19716, USA \\ 2. Department of Ocean Engineering, Univ. of Rhode Island, Narragansett, RI \\ 02882, USA \\ 3. Laboratoire SIAME, Université de Pau et des Pays de l'Adour, Anglet, France
}

June 19, 2015

\begin{abstract}
In their pioneering work, Ward and Day (2001) suggested that a large scale flank collapse of the Cumbre Vieja Volcano (CVV) on La Palma (Canary Islands) could trigger a mega-tsunami throughout the North Atlantic Ocean basin, causing major coastal hazard in the far-field. While more recent studies indicate that near-field waves from such a collapse would be more moderate than originally predicted by Ward and Day (Løvholt et al., 2008; Abadie et al., 2012), these would still be formidable and devastate the Canary Island, while causing major impact in the far-field at many locations along both the western European and US east coasts. Abadie et al. (2012) simulated tsunami generation and near-field tsunami hazard from a few CVV subaerial slide scenarios, with volumes ranging from 20 to $450 \mathrm{~km}^{3}$; the latter representing the most extreme scenario proposed by Ward and Day. They modeled tsunami generation, i.e., the tsunami source, using THETIS, a 3D Navier-Stokes (NS) multi-fluid VOF model in which slide material was considered as a heavy fluid. Near-field tsunami impact was then simulated for each source using FUNWAVE-TVD, a dispersive and fully nonlinear long-wave Boussinesq model (Shi et al., 2012; Kirby et al., 2013).

Here, using FUNWAVE-TVD for a series of nested grids of increasingly fine resolution, we model and analyze far-field tsunami hazard from two of Abadie et al.'s extreme CVV flank collapse scenarios: (i) that deemed the "credible worst case scenario" based on a slope stability analysis, with a $80 \mathrm{~km}^{3}$ volume; and (ii) the most extreme scenario, similar to Ward and Day's, with a $450 \mathrm{~km}^{3}$ volume. Simulations are performed using a one-way coupling scheme in between two given levels of nested grids. Based on simulation results, the overall tsunami hazard is first assessed in terms of maximum surface elevation computed along the western European, west African, and US east coasts (USEC). We then focus on the latter area, which is the object of high-resolution tsunami inundation mapping under the auspices of the US National Tsunami Hazard Mitigation Program. In this context, we compare the maximum surface elevation predicted along the coastline for each CVV scenario and show that, besides the initial directionality of the sources, coastal impact is mostly controlled by focusing/defocusing effects resulting from the shelf bathymetric features. A simplified ray tracing analysis confirms this controlling effect
\end{abstract}

$\dagger$ Now at Saint-Venant Lab. for Hydraulics, Université Paris-Est, Chatou F-78400 (C) 2015 Kluwer Academic Publishers. Printed in the Netherlands. 
of the wide USEC shelf for incident long waves. Finally, we present detailed results of high-resolution $(10 \mathrm{~m})$ inundation mapping for the most extreme CVV scenario, at one of the most vulnerable and exposed communities in the mid-Atlantic US states, in and around Ocean City, Maryland.

Keywords: Tsunami propagation; coastal geohazard; subaerial landslide; NavierStokes VOF model; Boussinesq wave models; volcano collapse; Cumbre Vieja, La Palma

\section{Introduction}

Since 2010, under the auspices of the US National Tsunami Hazard Mitigation Program (NTHMP), the authors have conducted modeling work to gradually develop tsunami inundation maps for the most critical or vulnerable areas of the US east coast (USEC). These first generation maps are constructed as envelopes of maximum inundation caused by the most extreme near- and far-field tsunami sources, both historical and hypothetical, in the Atlantic Ocean basin, without considering their return period or probability. Probabilistic tsunami hazard analyses will be part of future generations of inundation maps. To perform this inundation mapping work, all the relevant extreme tsunami sources in the Atlantic Ocean basin were first identified and parameterized, and then tsunami generation, propagation, and coastal impact from each of those was simulated to the considered areas of the US coastline. The extreme sources identified and used so far include (see ten Brink et al. (2014) for a more comprehensive review): (i) near-field submarine mass failures on or near the continental shelf break (Grilli et al., 2009; Grilli et al., 2015b); (ii) an extreme hypothetical M9 seismic event occurring in the Puerto Rico Trench (Grilli et al., 2010); (iii) a repeat of the historical 1755 M8.9 earthquake occurring in the Azores convergence zone (Barkan et al., 2009); and (iv) a large scale volcanic flank collapse of the Cumbre Vieja Volcano (CVV) in the Canary Archipelago, which is the object of this paper.

Large subaerial landslides are known to occur on the flanks of active volcanos (a.k.a. volcanic flank collapses), because volcanic material continuously accumulates until the slope becomes unstable (Holcomb and Searle, 1991). Large deposits from past landslides have been found on the seafloor surrounding young volcanos in Hawaii (Moore et al., 1989; Robinson and Eakins, 2006) and Réunion Island (Cochonat et al., 1990; Oehler et al., 2004). In the Canary Islands, Masson et al. (2002) identified at least 14 large paleo-landslides, associated with failures that occurred in the last one million years on the flanks of the youngest volcanoes in the islands of El Hierro, La Palma, and Tenerife (with 
the youngest one, at El Hierro, being only 15,000 years old; Figs. 1 and 2). Some of these landslides had volumes of $\mathrm{O}\left(100 \mathrm{~km}^{3}\right)$ or more and could have triggered mega-tsunamis (Ward and Day, 2001). It is believed that such large, potentially catastrophic, events may have occurred in average every 100,000 years in the Canary Archipelago, which is a much longer return period than the typical hundreds of year periodicity of megathrust seismic events in large subduction zones (e.g., in the Atlantic Ocean basin, Grilli et al. (2010) estimated 200 and 600 year return periods for M8.7 and M9.1 earthquakes, respectively, in the Puerto Rico Trench), which have the potential of causing large tsunamis. A long return period, however, does not necessarily mean low risk, particularly regarding tsunami hazard for critical coastal facilities, such as nuclear power plants or large maritime terminals. Therefore, comprehensive tsunami hazard assessment for such critical facilities must consider all the potential extreme tsunami sources in the relevant ocean basin, such as the volcanic flank collapses considered here. More detailed analyses of landslides mechanisms in the Canary Islands and of their recurrence are outside the scope of this paper, but the reader can consult the works of Wynn and Masson (2003) and Hunt et al. (2011; 2013), for more information. It should be noted that the latter three studies provide evidence for a multi-stage failure, which was not considered here in our extreme scenarios,

In the Canary Islands, CVV (Figs. 1 and 2) is the fastest growing volcano (Carracedo et al., 1999), with the potential of causing very large flank collapses and thus of generating a mega-tsunami. Ward and Day (2001) were the first to suggest this possibility, by considering an extreme collapse of nearly the entire CVV western flank, with an estimated $500 \mathrm{~km}^{3}$ volume. Using fairly simple models, they simulated the resulting tsunami generation and propagation and predicted extremely large (kilometer high) near-field waves which, despite significant decay in the far-field, would still be on the order of 10-20 m, when reaching the USEC. Because they used simplified models to estimate coastal impact, which in particular lacked dissipation, they concluded that flow depths on the order of 10-20 m could occur along the USEC, depending on location. Other authors later recognized the potential for the generation of large waves from an extreme CVV collapse, but questioned both Ward and Day's catastrophic landslide scenario and nearshore wave modeling (Mader, 2001; Pararas-Carayannis, 2002). In more recent work, Ward and Day's and other similar CVV collapse scenarios were modeled using more accurate models of both landslide and wave generation/propagation (Pérignon, 2006; Løvholt et al., 2008; Zhou et al., 2011; Abadie et al., 2012). 


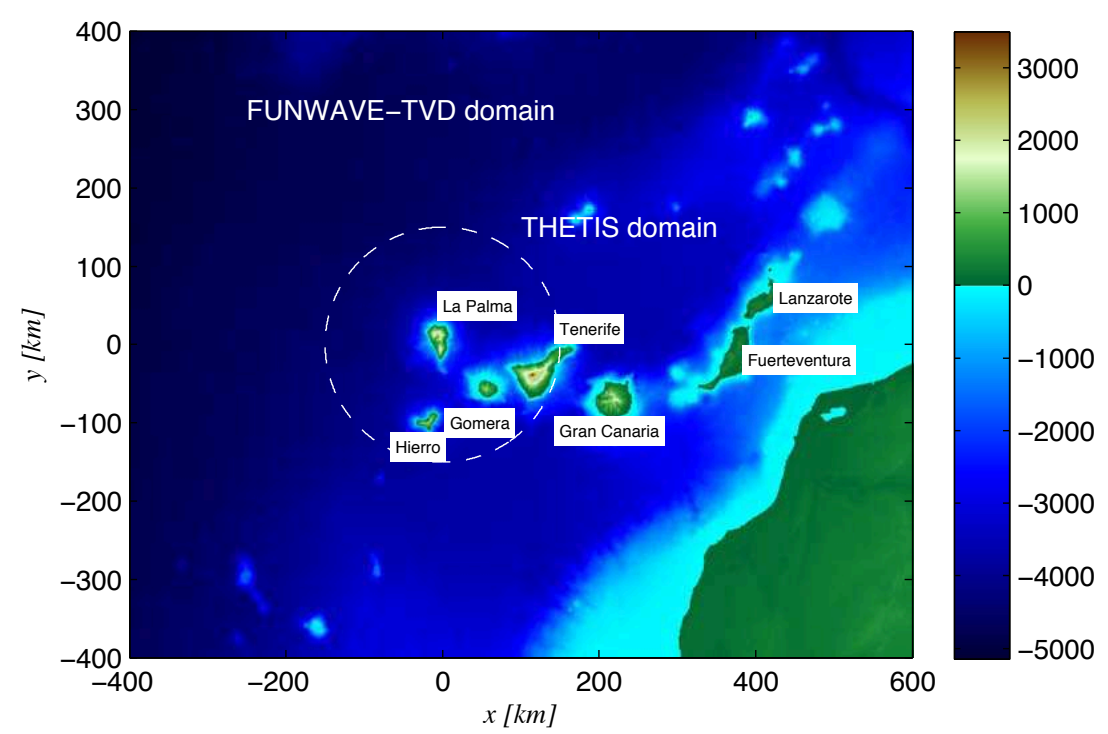

Figure 1. Computational domains covering the Canary Islands, including the higher resolution 3D THETIS domain surrounding La Palma (dashed circle) and the $500 \mathrm{~m}$ resolution FUNWAVE-TVD domain (outer box). Bathymetry $(<0)$ and topography $(>0)$ are represented by the color scale (meter).

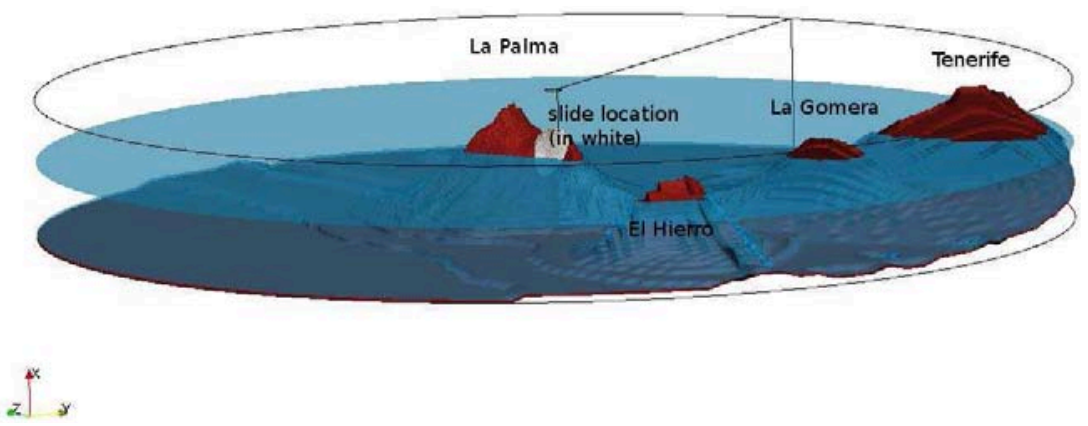

Figure 2. Sketch of THETIS 3D computational domain for the simulation of landslide tsunami generation. The white area in La Palma indicates the site of the 80 $\mathrm{km}^{3}$ subaerial slide. See Abadie et al. (2012) for details.

Abadie et al. (2012) provided a review to date of relevant CVV landslide and tsunami modeling studies. Based on a slope stability analysis of the CVV western flank (Riss et al., 2010), they estimated both the geometry and volume of the most plausible extreme flank collapse scenario. Although they found high safety factors, greater than one, in all the cases they analyzed, the lowest one was obtained for an $80 \mathrm{~km}^{3}$ failure, which they thus deemed the likeliest extreme flank 
collapse scenario; here we will refer to this case instead as: extreme credible worst case scenario or ECWCS, which is more standard in hazard analysis. While the return period for such an event is unknown, it can be estimated to be $\mathcal{O}(100,000)$ years, which is the age of deposits from earlier flank collapses found at the toe of the volcano. despite being stable under present conditions, the CVV western flank could be destabilized by a large earthquake or volcanic eruption, and a slide be triggered (this mechanism is supported by recent field work; S. Day, personal communication, 2014). In addition to their likeliest scenario, to compare their model results to those of earlier studies such as Løvholt et al.'s, which considered only the most catastrophic scenario proposed by Ward and Day, Abadie et al. also modeled a similar extreme CVV western flank collapse scenario, with a volume estimated at $450 \mathrm{~km}^{3}$, based on higher resolution bathymetry and topography. Finally, they modeled two more scenarios representing partial failure of their likeliest scenario, with 20 and $40 \mathrm{~km}^{3}$ volumes, respectively.

In the simulations of these 4 scenarios, Abadie et al. used the threedimensional (3D) multi-material Navier-Stokes model THETIS, in which the slide material was modeled as a heavy Newtonian fluid. [THETIS was developed since 1996 by the TREFLE CNRS laboratory, at the University of Bordeaux, France (http://thetis.enscbp.fr).] THETIS has been validated for modeling wave generation by rigid (Abadie et al., 2010) and deformable (Morichon and Abadie, 2010) slides; additionally the model has been used to simulate breaking waves (Abadie et al., 1998; Lubin et al., 2006). Once the landslide tsunamis were fully generated in the 3D model (which was assessed by quantifying the slide-to-water energy transfer), near-field tsunami propagation within the Canary Islands area was simulated using the two-dimensional (2D) fully nonlinear and dispersive long wave model FUN- WAVE-TVD (Shi et al., 2012), in a $500 \mathrm{~m}$ resolution Cartesian grid (Fig. 1). The model was initialized 5 minutes into the event, based on the depth-averaged horizontal velocity and surface elevation computed with THETIS (see details in Abadie et al. (2012)). These simulations predicted initial wave elevations in front of the volcano of up to $1200 \mathrm{~m}$ for the $450 \mathrm{~km}^{3}$ scenario and $800 \mathrm{~m}$ for the $80 \mathrm{~km}^{3}$ scenario (Fig. 3), with the dominant direction of wave propagation towards the far-field being at $24^{\circ}$ south of West. For both scenarios, runup was calculated to be over $100 \mathrm{~m}$ in the back of the La Palma island and 10-50 m on nearby islands, 10-25 min into the event. Details of near-field impact can be found in Abadie et al. (2012).

In this paper, our main goal is to model and assess the far-field tsunami hazard resulting from the two largest CVV flank collapse scenarios studied by Abadie et al.: (i) the ECWCS with a $80 \mathrm{~km}^{3}$ volume; 
and (ii) the most extreme one with a $450 \mathrm{~km}^{3}$ volume. Because of our NTHMP project of developing tsunami inundation maps for the USEC, based on the most extreme tsunami sources identified in the Atlantic Ocean basin, we first focus our work on this area and present in greater details, results of tsunami propagation and far-field impact for the most extreme $450 \mathrm{~km}^{3}$ flank collapse scenario. Besides maximum flow depth along the entire coastline, we show detailed results in finer nested grids for one of the most exposed areas of the US east coast, near and around Ocean City, MD. Then, for the purpose of comparison, limited results of the $80 \mathrm{~km}^{3}$ scenario simulations are presented and compared to the former. As an additional goal, we also model the farfield impact of both CVV scenarios on the very exposed, and closer to the source, western European and north African coasts. Here, similar to the near-field tsunami hazard study performed by Abadie et al. (2012), we essentially consider the ECWCS $80 \mathrm{~km}^{3}$ scenario and provide limited results for the extreme scenario, for comparison.

(a)

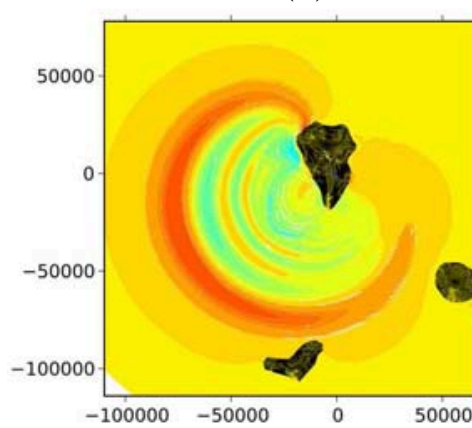

(b)

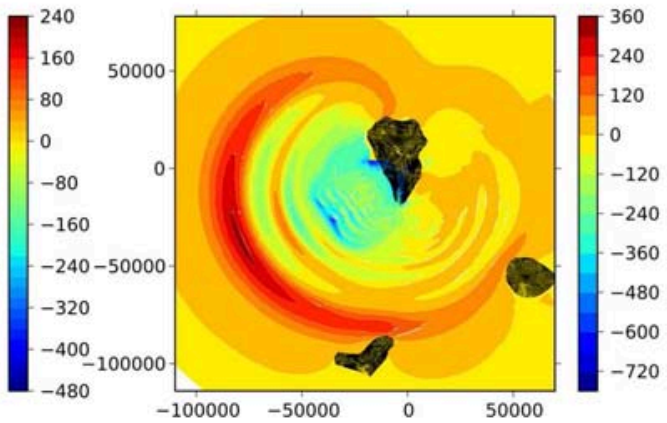

Figure 3. Surface elevations (color scale in meter) computed with THETIS for CVV flank collapse scenarios with volume: (a) 80 , (b) $450 \mathrm{~km}^{3}$, at $t=7.5 \mathrm{~min}$ after the start of the event. Note, $x$ and $y$ axes represent distance in meter.

\section{Modeling of landslide tsunami generation}

We perform far-field simulations of tsunami propagation and coastal impact for two extreme scenarios of CVV flank collapse: (i) the ECWCS failure with $80 \mathrm{~km}^{3}$ of slide material; and (ii) the most extreme one with $450 \mathrm{~km}^{3}$. Figures 1 and 2 show the footprint and perspective view, respectively, of the 3D computational domain used by Abadie et al. (2012) in their computations with THETIS of the volcano collapse and initial tsunami generation. This domain was discretized by a cylindrical 


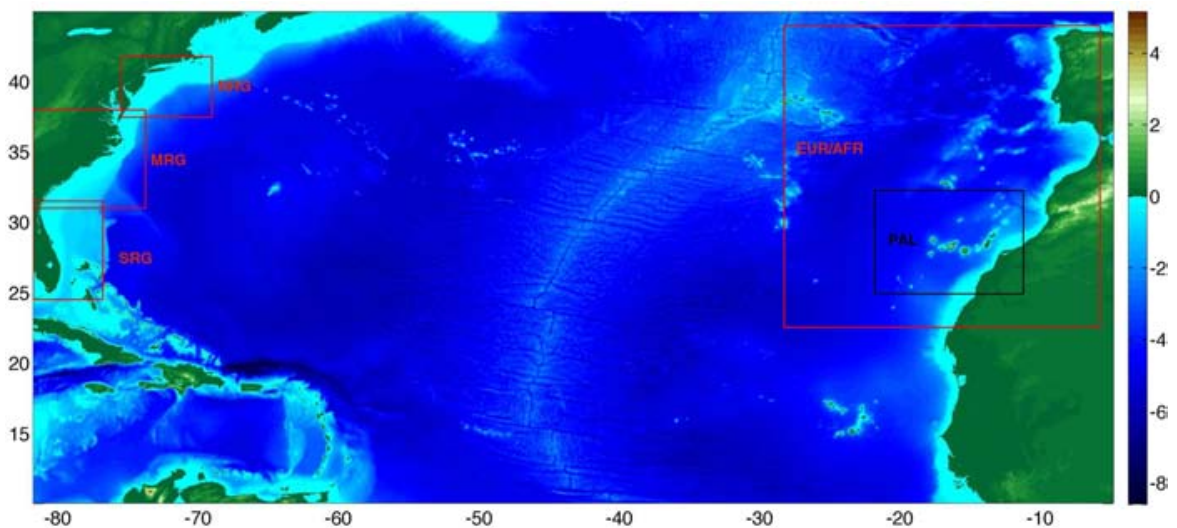

Figure 4. FUNWAVE-TVD simulation grids (see Table I): (PAL) $500 \mathrm{~m}$ local Cartesian grid around La Palma (black box); 1 arc-min spherical Atlantic grid (outer box); 20 arc-sec spherical regional grids for simulating far-field coastal effects on the USEC (red boxes): (NRG) Northern USEC regional, (MRG) Middle USEC regional, (SRG) Southern USEC regional, grids; (EUR/AFR) 15 arc-sec spherical regional grid for simulating far-field coastal effects in western Europe and western Africa. Color scale indicates bathymetry $(<0)$ and topography $(>0)$ in $\mathrm{km}$.

mesh $(8 \mathrm{~km}$ tall and $150 \mathrm{~km}$ radius; 300 by 80 stretched grid cells in the radial and vertical directions, and 140 grid cells in the tangential direction). The slide area marked in white on Figure 2 corresponds to the $80 \mathrm{~km}^{3}$ volume. Besides the island of La Palma, El Hierro, La Gomera, and Tenerife were included in the domain, since their bathymetry and topography affected the early stages of wave propagation. Similar to Gisler et al. (2006), Abadie et al. modeled the CVV slide debris flow as an inviscid fluid with a constant $2,500 \mathrm{~kg} / \mathrm{m}^{3}$ density (i.e., corresponding to basalt). Hence, no basal friction nor resistance to internal deformation were modeled, which they indicated causes more energetic and dynamic slides, likely to generate worst case scenario tsunamis, that are conservative as far as coastal hazard assessment.

Figure 3 shows the surface elevations computed with THETIS at $t=7.5 \mathrm{~min}$, for the two slide scenarios. The directivity of tsunami waves is similar in both cases, with a dominant direction of wave propagation at about $24^{\circ}$ south of West, but the maximum surface elevation of the generated leading tsunami wave increases and occurs farther away from the volcano for the larger slide volume (as a result of amplitude dispersion effects). The reader will be referred to Abadie et al. (2010; 2012) for details of the THETIS model features, set-up, and application to the CVV landslide tsunami simulations. 
Table I. Latitudinal and longitudinal extension, and resolution, for FUNWAVE-TVD simulation grids of Fig. 4.

\begin{tabular}{r||c|c|c} 
Grid & Latitude & Longitude & Resolution \\
\hline Local Palma & $24.8706^{\circ}-32.2337^{\circ} \mathrm{N}$ & $-22.0184^{\circ}--11.4356^{\circ} \mathrm{E}$ & $500 \mathrm{~m}$ \\
Atlantic Basin & $10.0^{\circ}-45.0^{\circ} \mathrm{N}$ & $-82.0^{\circ}--5.0^{\circ} \mathrm{E}$ & $1^{\prime}$ \\
N. US reg. & $37.45^{\circ}-41.7667^{\circ} \mathrm{N}$ & $-75.7^{\circ}--69.25^{\circ} \mathrm{E}$ & $20^{\prime \prime}$ \\
Mid US reg. & $31^{\circ}-38^{\circ} \mathrm{N}$ & $-82^{\circ}--74^{\circ} \mathrm{E}$ & $20^{\prime \prime}$ \\
S. US reg. & $24.5^{\circ}-31.5^{\circ} \mathrm{N}$ & $-82.0^{\circ}--77^{\circ} \mathrm{E}$ & $20^{\prime \prime}$ \\
W. Europe & $22.5^{\circ}-44.0^{\circ} \mathrm{N}$ & $-28.5^{\circ}--6.0^{\circ} \mathrm{E}$ & $15^{\prime \prime}$ \\
and W. Africa & & &
\end{tabular}

\section{Modeling of near- and far-field tsunami impact}

Because THETIS is computationally expensive (the 3D simulations in Abadie et al.'s (2012) run for a few days to a week on 500 processors) and the generated landslide tsunami waves quickly become long waves as they propagate away from CVV, Abadie et al. (2012) simulated tsunami impact in the near-field, beyond the $150 \mathrm{~km}$ radius of the THETIS domain, with the 2D-horizontal Boussinesq Model (BM) FUNWAVE-TVD, in a $500 \mathrm{~m}$ resolution Cartesian grid (Fig. 1). [To correct for earth's sphericity, a transverse secant Mercator projection was used, with its origin located at $28.5 \mathrm{~N}$ and $18.5 \mathrm{~W}$. ] While still computationally intensive, most simulations with FUNWAVE-TVD reported here typically run for a few hours to half a day on 24 processors (see details below). FUNWAVE-TVD's near-field simulations were initialized using surface elevations (such as shown in Fig. 3) and depth-averaged horizontal velocities computed with THETIS, at 5 min into the event, which ensured that both the slide had fully transferred its energy to the water motion and the generated tsunami had not yet reached the neighboring island. Since THETIS and FUNWAVE-TVD have different dimensionality and physics, to provide for a smooth transition of simulations from one model to the other, a filter was applied to THETIS' results to eliminate residual oscillations and vortices in the generated wave train tail near the volcano, that would otherwise perturb FUNWAVE simulations and could possibly trigger instabilities (due to differences in model equations, dimensionality and treatment of horizontal vorticity). By running THETIS for a longer time, Abadie et al. verified that the filtering method was accurate and did not affect the subsequent near- and far-field wave propagation. Details can be found in the reference. 
As they include frequency dispersion effects, BMs simulate more complete physics than models based on Nonlinear Shallow Water Equations (NSWE), which until recently were traditionally used to model co-seismic tsunami propagation. Dispersion is key to accurately simulating landslide tsunamis, which usually are made of shorter and hence more dispersive waves than for co-seismic tsunamis (Watts et al., 2003; Grilli and Watts, 2005; Mohammed and Fritz, 2012). However, dispersion is also key to model the coastal impact of any tsunami since dispersive shock waves (a.k.a undular bores) can be generated near the crest of long waves in increasingly shallow water (Madsen et al., 2008; Geist et al., 2009; Grilli et al., 2012; Grilli et al., 2015b). A review of dispersive effects in tsunamis can be found in Glimsdal et al. (2013).

FUNWAVE-TVD is based on the equations of Shi et al. (2012) and is a recent improvement of FUNWAVE (Wei et al., 1995), which was originally developed and used to model coastal and nearshore waves, but was later also applied to a variety of tsunami case studies, both landslide and co-seismic (Watts et al., 2003; Days et al., 2005; Grilli et al., 2007; Ioualalen et al., 2007; Tappin et al., 2008; Karlsson et al., 2009; Grilli et al., 2010; Grilli et al., 2013; Tappin et al., 2014). The importance of dispersive effects in far-field tsunami propagation was illustrated in case studies, by running the model in both BM and NSWE modes, by Tappin et al. (2008) for the 1998 Papua New Guinea landslide tsunami and by Ioualalen et al. (2007) for the 2004 Indian Ocean and Grilli et al. (2013) for the 2011 Tohoku, coseismic tsunamis.

FUNWAVE-TVD was developed as a fully nonlinear version in Cartesian coordinates (Shi et al., 2012), but currently is only implemented as a weakly nonlinear approximation in spherical coordinates, including Coriolis effects (Kirby et al., 2013). Both versions of the model use a combined finite-volume and finite-difference MUSCL-TVD scheme. As in the earlier FUNWAVE version, improved linear dispersion properties are achieved, up to nearly the deep water limit, by expressing the $\mathrm{BM}$ equations in terms of the horizontal velocity vector computed at 0.531 times the local depth. Additionally, wave breaking dissipation is adequately modeled by switching from the Boussinesq to the NSWE equations when the local height to depth ratio exceeds 0.8 (which has been shown to closely approximate the physical dissipation in breaking waves). Bottom friction is parameterized as a quadratic term based on a friction coefficient $C_{d}$; in all the present simulations, we use the standard value for coarse sand, $C_{d}=0.0025$, which only causes moderate dissipation over shallow shelves and hence is conservative as far as predicting maximum flow depth at the coastline; see Geist et al. (2009) and Grilli et al. (2015b) for a study of the influence of bottom friction on landslide tsunami nearshore propagation and coastal impact. 
Additional discussions in this respect can be found in Kaiser et al. (2011). FUNWAVE-TVD's latest implementation is fully parallelized using MPI, for efficient use on large computer clusters (a nearly $90 \%$ scalability is achieved; all simulations reported in this paper for the oceanic propagation were performed using $24 \mathrm{CPUs}$ and those in the many finer coastal nested grids used hundreds of CPUs). FUNWAVETVD was fully validated against all of NOAA's National Tsunami Mitigation Program (NTHMP) mandatory benchmarks (Tehranirad et al., 2011).

(a)

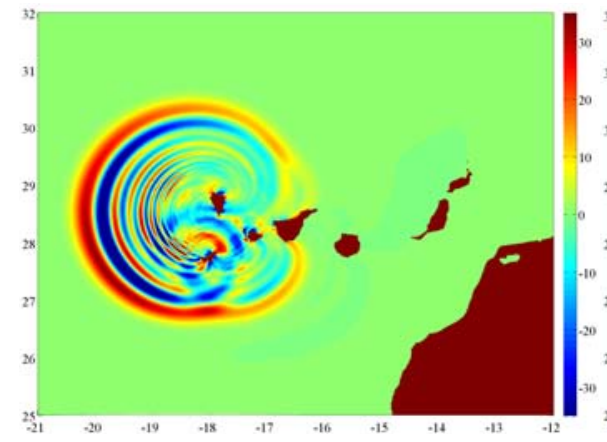

(c)

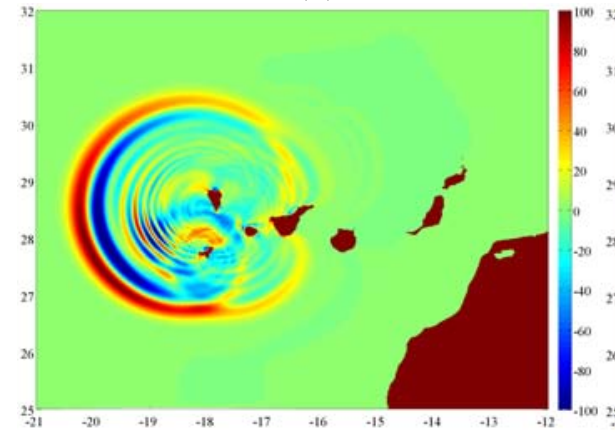

(b)

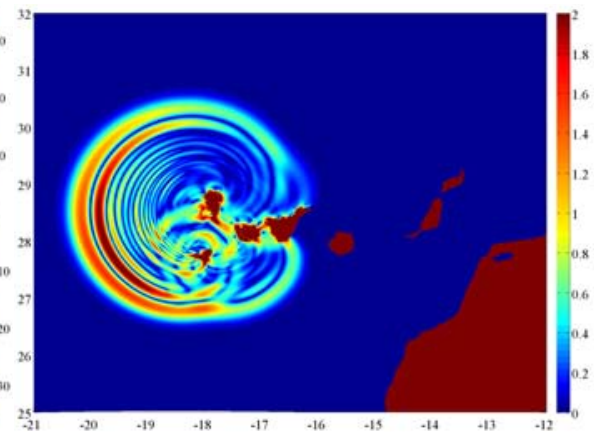

(d)

Figure 5. (a,c) Surface elevation (color scale in meter) and (b,d) horizontal water velocity magnitude (color scale in $\mathrm{m} / \mathrm{s}$ ) computed with FUNWAVE-TVD in the 500 m Cartesian grid defined in Fig. 1, at 20 min after the start of the CVV event, for Abadie et al.'s (2012): (a,b) $450 \mathrm{~km}^{3}$; and (c,d) $80 \mathrm{~km}^{3}$ flank collapse scenarios.

We simulate the transoceanic tsunami propagation of each CVV scenario using the spherical version of FUNWAVE-TVD, initially in a 1 arc-min Atlantic ocean basin grid; we then pursue simulations in nested regional coastal grids: three 20 arc-sec (about $610 \mathrm{~m}$ ) resolution grids along the USEC and one 15 arc-sec (about $450 \mathrm{~m}$ ) resolution grid along the north African and western European coasts (Fig. 4). Following the 
methodology established in our NTHMP inundation mapping work, simulations of tsunami coastal impact along the USEC are performed in a series of nested Cartesian grids (to use the fully nonlinear implementation of the model), based on results of the 3 regional grids, with a reduction by a factor of 3 or 4 in mesh size, from one coarser grid level down to a finer grid level. The finest grid resolution used in the inundation maps is 10 to $30 \mathrm{~m}$, depending on the complexity of the coastal features, which typically requires 3 or 4 additional levels of nested grids beyond the 20 arc-sec US regional grids. This will be illustrated in results of inundation mapping around Ocean City, MD, presented later.

Bathymetry in the 1 arc-min Atlantic basin grid is interpolated from the ETOPO-1 database (i.e., 1 arc-sec accurate data). In the US regional grids, bathymetry is interpolated over the continental shelf from NOAA's 3 arc-sec (about $90 \mathrm{~m}$ ) Coastal Relief Model (CRM) data, and in the African and European regional grid from the $500 \mathrm{~m}$ resolution EMODNET data set (http://portal.emodnet-hydrography.eu). For the finer coastal nested grids, bathymetry and topography from the $10 \mathrm{~m}$ resolution NOAA tsunami Digital Elevation Maps (DEMs) are used, wherever available, and if not, the similar resolution FEMA DEMs are used. Table I gives the extent of the Atlantic ocean basin and regional simulation grids.

Simulations in the 1 arc-min Atlantic ocean basin grid are initialized using the surface elevation and horizontal velocity computed at 20 min into the event in the $500 \mathrm{~m}$ grid (Fig. 1), which are shown in Fig. 5 for the 80 and $450 \mathrm{~km}^{3}$ flank collapse scenarios. At this time, for both sources, the tsunami is made of a large number of quasicircular concentric waves, with the leading elevation wave being 15-40 $\mathrm{m}$ and 40-100 $\mathrm{m}$ high for each source, respectively, and the largest values occurring in the predominant direction of propagation, at $24^{\circ}$ south of West. The leading crest is followed by a deep trough and a long oscillatory dispersive tail with at least 5 significant waves. This pattern will also be observed in far-field results. A detailed analysis of the features and decay patterns during propagation to the far-field of the tsunami wave train, computed for each source, can be found in Abadie et al. (2012). For the simulations in the 15 arc-sec regional grid, encompassing western Europe and western Africa, because this grid includes the Canary Islands, computations with FUNWAVE-TVD are simply initialized based on the source computed 20 min into the event, as for the 1 arc-min grid. All the nested grid simulations in 20 arc-sec regional grids and finer Cartesian grids along the US east coast are performed using a one-way coupling scheme, which works by computing time series of free surface elevations and currents in a 
Table II. Locations of stations used to compute time series of incident tsunami for CVV flank collapse scenarios shown in Fig. 8 (see Fig. $7 \mathrm{~b}$ for location).

\begin{tabular}{r||c|r|r|r} 
Location & $\begin{array}{r}\text { Map } \\
\text { index }\end{array}$ & $\begin{array}{r}\text { Latitude } \\
\text { (Deg. E) }\end{array}$ & $\begin{array}{r}\text { Longitude } \\
(\text { Deg. N) }\end{array}$ & $\begin{array}{r}\text { Depth } \\
(\mathrm{m})\end{array}$ \\
\hline Offshore of NH,ME & $\mathrm{a}$ & -66.6318 & 40.9542 & 200 \\
Offshore of NY,RI & $\mathrm{b}$ & -71.1429 & 40.0837 & 200 \\
Offshore of NJ,MD & $\mathrm{c}$ & -74.3086 & 37.7094 & 200 \\
Offshore of SC & $\mathrm{d}$ & -77.9096 & 32.8421 & 200 \\
Offshore of FL & $\mathrm{e}$ & -79.8882 & 27.5791 & 200 \\
Bahamas & $\mathrm{f}$ & -77.7118 & 27.1834 & 800
\end{tabular}

coarser grid level, for a large number of numerical gages (stations) defined along the boundary of the finer grid level. Computations in the finer nested grid level are then performed using these time series as boundary conditions. In this scheme, reflected waves propagating from the area covered by each finer grid are included in the time series computed in the coarser grids, along the finer grid boundaries, thus satisfying an open boundary condition. To reduce reflection in the first coarsest grid level (here either the 1 arc-min Atlantic ocean basin grid for the westward propagation, or the 15 arc-sec grid for the propagation towards western Africa and Europe), $200 \mathrm{~km}$ thick sponge (absorbing) layers are specified along all the open boundaries.

\section{Transatlantic tsunami propagation to the far-field}

Because the overall features and patterns of tsunami waves generated by both CVV flank collapse scenarios are similar, and we focus on the most extreme tsunami sources, in the following, we only detail the propagation to the far-field of the extreme $450 \mathrm{~km}^{3}$ scenario and its impact along the US east coast; in north Africa and western Europe, consistent with the earlier work of Abadie et al. (2012), we detail instead the impact of the $80 \mathrm{~km}^{3}$ scenario. Whenever relevant to the discussion, however, results of the other scenario are also shown.

Figure 6 shows three snapshots of surface elevation computed in the 1 arc-min grid for the $450 \mathrm{~km}^{3}$ scenario. In Fig. 6a, 1h20' into the event, the tsunami has already reached and impacted the western coast of Africa, in the Sahara and Morocco. In Fig. 6b, 2h20' into the event, 
(a)

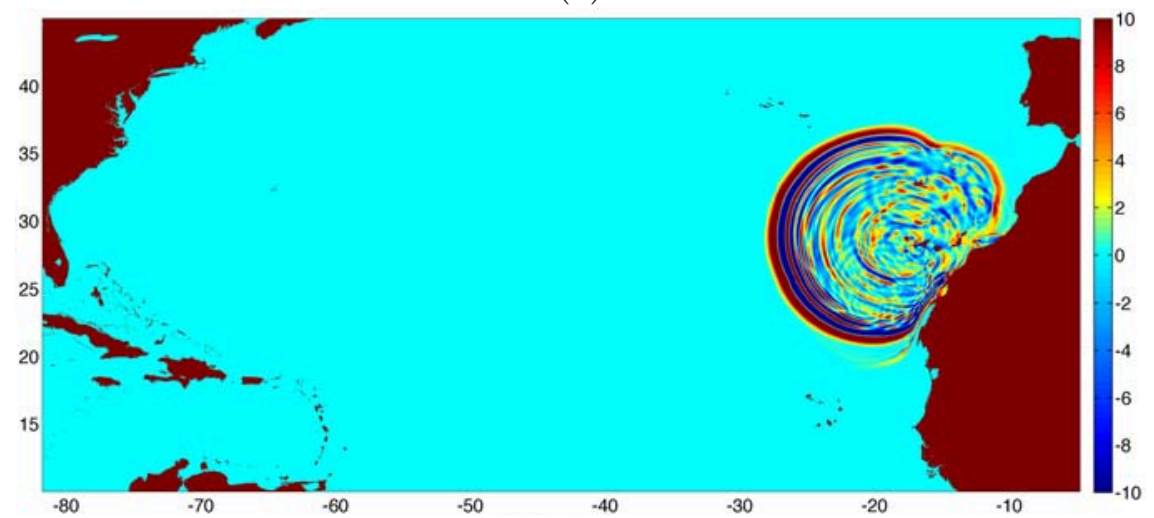

(b)

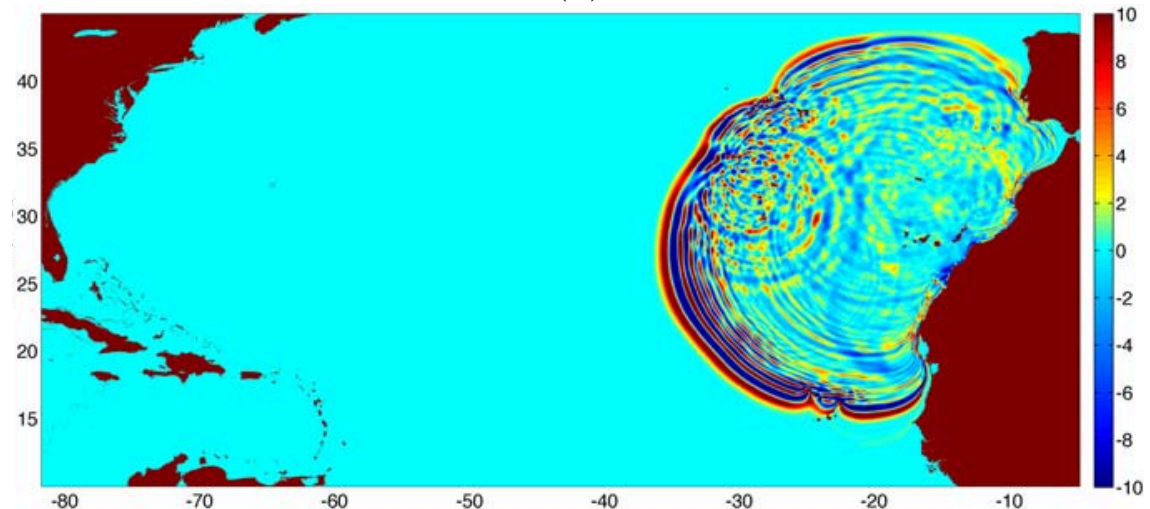

(c)

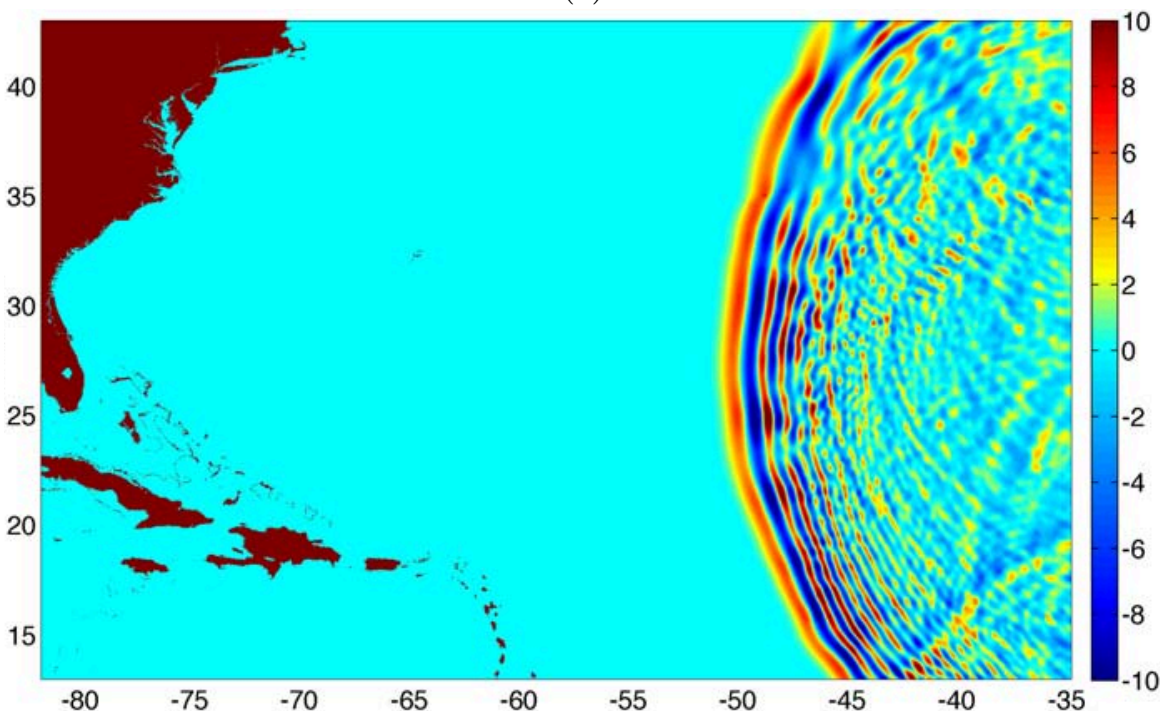

Figure 6. Surface elevation (color scale in meter) for the CVV $450 \mathrm{~km}^{3}$ flank collapse scenario, computed with FUNWAVE-TVD in the 1 arc-min Atlantic ocean basin grid, at: (a) 1h20'; (b) 2h20'; and (c) 4h20', into the event. Axes are Long. E. (deg.) and Long. N. (deg.). 
(a)

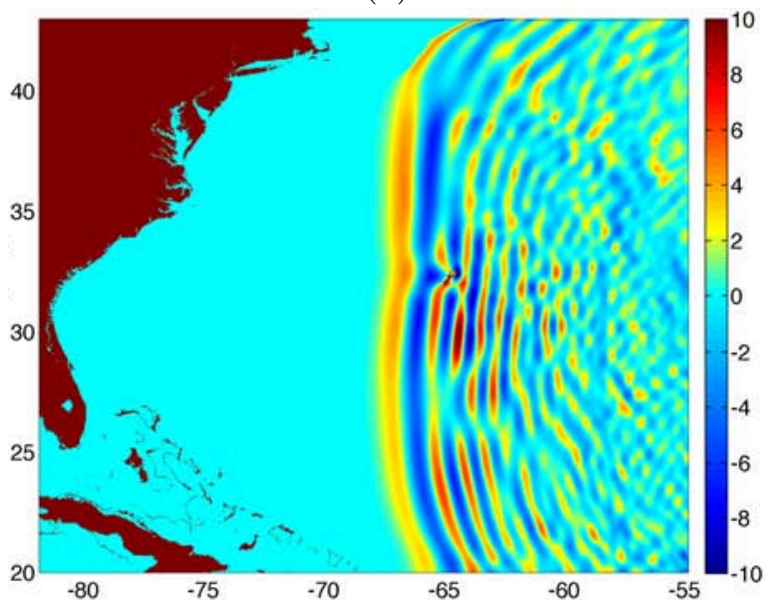

(b)

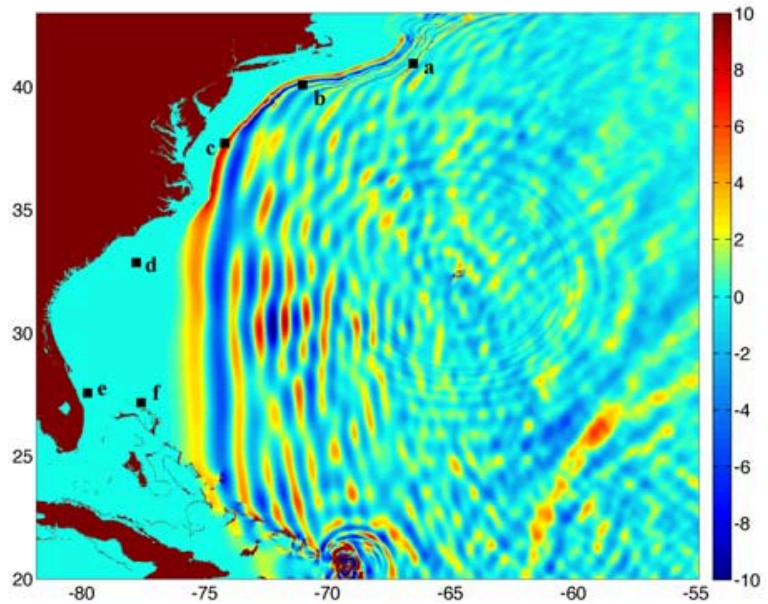

(c)

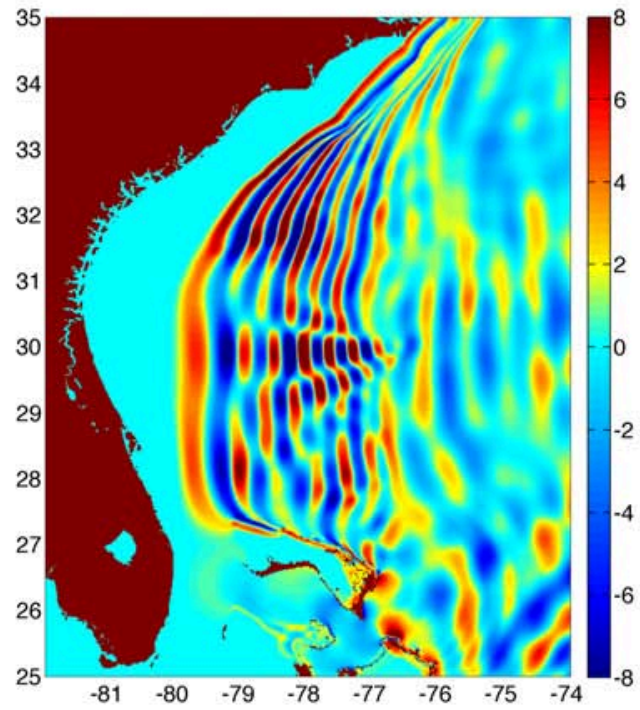

Figure 7. Surface elevation (color scale in meter) for the CVV $450 \mathrm{~km}^{3}$ flank collapse scenario, computed with FUNWAVE-TVD in the 1 arc-min Atlantic ocean basin grid, at: (a) 6h20'; (b) 7h20'; and (c) 8h20', into the event. Axes are Long. E. (deg.) and Long. N. (deg.). Locations of stations a-f defined in Table II, with time series plotted in Fig. 8, are shown in (b). 

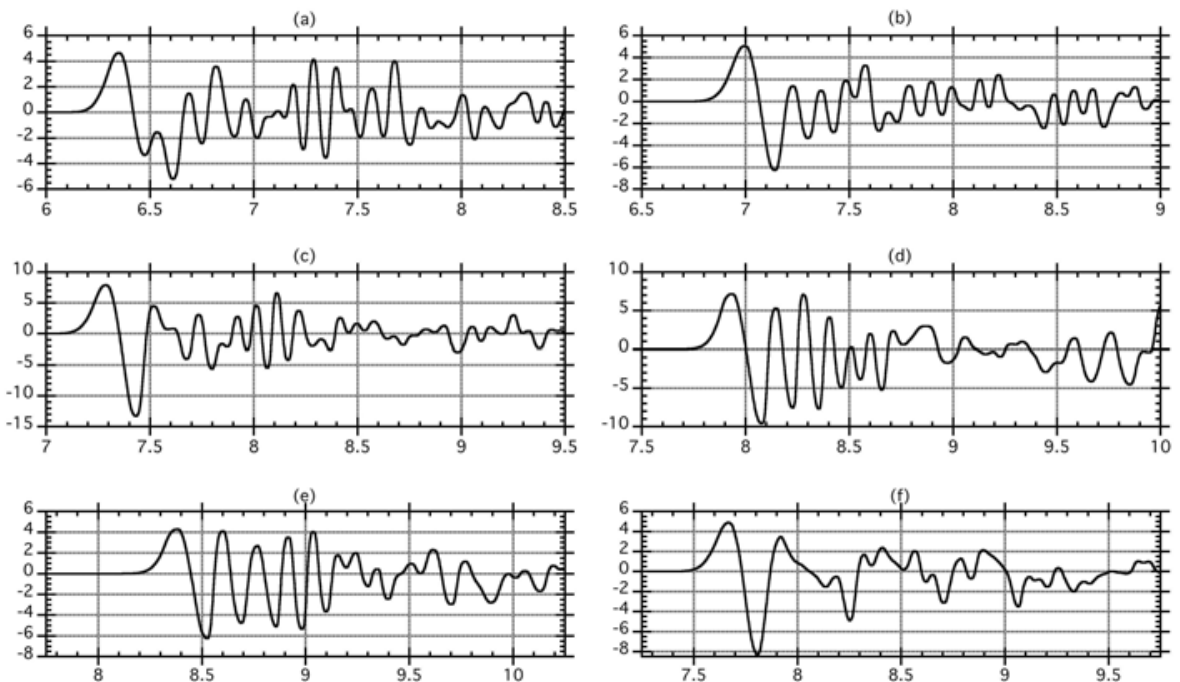

Figure 8. Time series of surface elevation ( $x$-axis in hour and $y$-axis in meter) for the CVV $450 \mathrm{~km}^{3}$ flank collapse scenario, computed at stations a-f (see Table II and Fig. 7b for location) with FUNWAVE-TVD, in the 1 arc-min Atlantic Ocean basin grid.

the tsunami has reached the southern part of the western European coast and is about to enter the Mediterranean sea by the Strait of Gibraltar. In Fig. 6c, 4h20' into the event, the tsunami has propagated about half-way into the Atlantic Ocean and has a long-crested front made of 4 to 5 major waves, with 8-10 m maximum amplitude.

Figure 7 shows three additional, slightly zoomed-in, snapshots of surface elevations computed in the 1 arc-min grid, that detail the far-field tsunami propagation towards the US east coast, for the CVV $450 \mathrm{~km}^{3}$ flank collapse scenario. As the tsunami reaches the shallower waters of the north American continental slope and shelf, first in the north and gradually towards the south, waves slow down, reduce their wavelength (bunching up together), and refract towards the coast, bending in a way that their crests gradually follow bathymetric contours. In Fig. $7 \mathrm{~b}, 7 \mathrm{~h} 20^{\prime}$ into the event, the tsunami is reaching the shelf bordering the upper USEC, from Cape Cod to North Carolina. In Fig. 7c, 8h20' into the event, the tsunami is reaching the shelf off of South Carolina and is approaching Florida and Georgia. We see that off of Florida, the tsunami dispersive tail has increased to 7 significant waves, with 6 to $8 \mathrm{~m}$ maximum amplitude. This wave train pattern is clearer on the time series of surface elevation plotted in Fig. 8, for 6 stations whose locations are defined in Table II and marked in Fig. 7b. The first five 
(a)

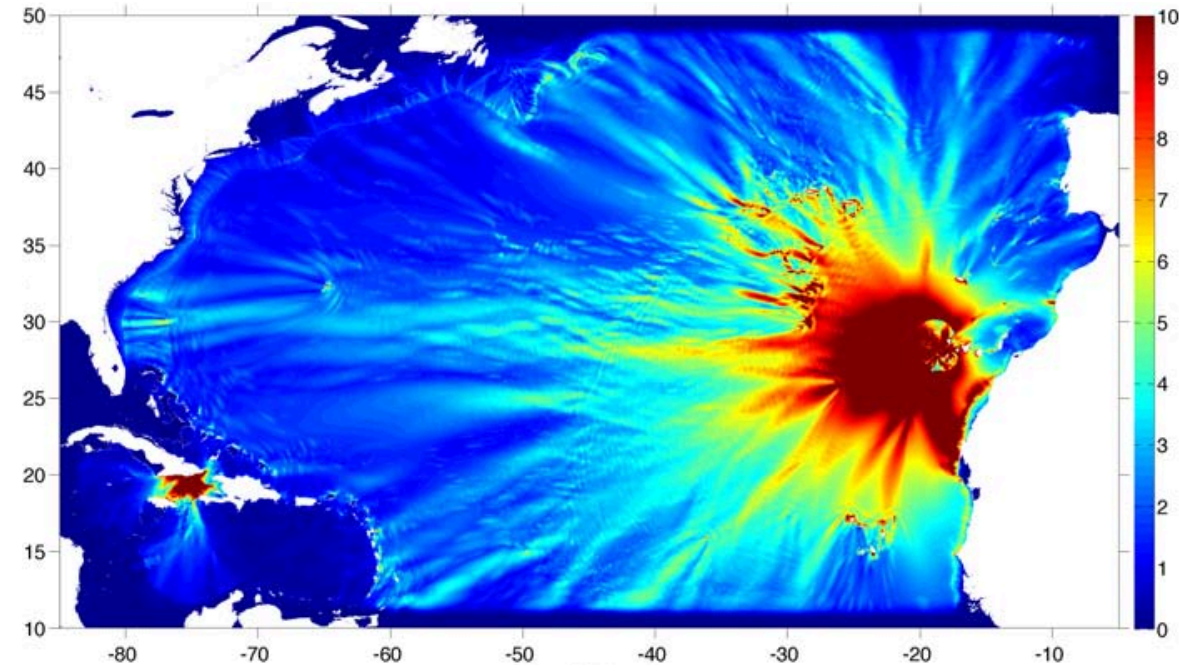

(b)

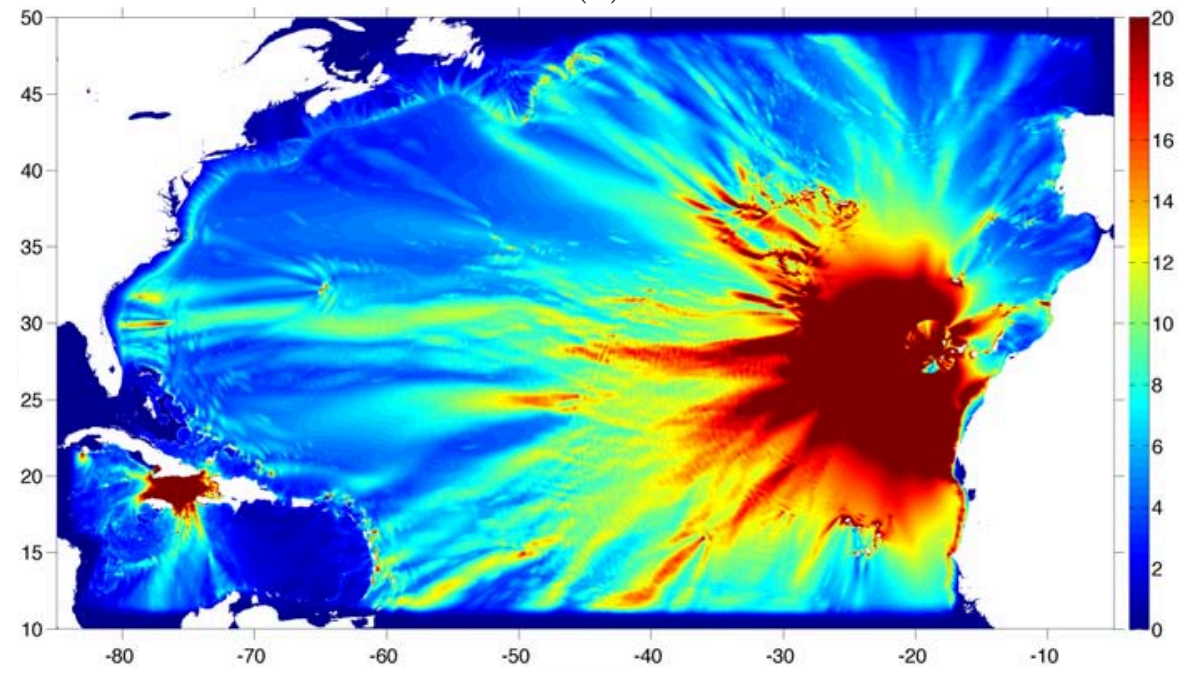

Figure 9. Maximum envelope of surface elevation (color scale in meter) computed with FUNWAVE-TVD in 1 arc-min Atlantic Ocean basin grid for the tsunami generated by the: (a) $80 \mathrm{~km}^{3}$; and (b) $450 \mathrm{~km}^{3}$, CVV flank collapse scenarios. Axes are Long. E. (deg.) and Long. N. (deg.). [Note that both figures are plotted with a different color scale. Also note the large elevations, in both cases, west of Haiti and south of Cuba are an artifact of numerical simulations; more accurate simulations and details of the extreme CVV scenario impact in this area can be found in Grilli et al. (2015a).] 
stations "a-e" are located in a $200 \mathrm{~m}$ depth offshore of important cities or areas of the USEC, from Maine (ME) to Florida (FL) from north to south, while the last one " $\mathrm{f}$ " is located in a $800 \mathrm{~m}$ depth off of the Bahamas. At stations a-e, the incident tsunami wave train has at least 3 large leading waves, with an average period of 9-12 min. The leading wave height (trough to crest) is about $10 \mathrm{~m}$ at the first two stations in the north, $18-21 \mathrm{~m}$ at the middle two stations, and about $10 \mathrm{~m}$ again at the southern station. At the last station $\mathrm{f}$, in deeper water, the wave train is less organized, but the first three waves have an average period of about $13 \mathrm{~min}$ and the leading wave height is nearly $14 \mathrm{~m}$.

Figure 9 finally shows the envelopes of maximum surface elevation computed in the 1 arc-min Atlantic Ocean basin grid, for the $80 \mathrm{~km}^{3}$ and $450 \mathrm{~km}^{3} \mathrm{CVV}$ flank collapse scenarios. In both cases, we see a significant variation (alongshore modulation) in the maximum wave height in the far-field, resulting both from the directionality of the tsunami source (Fig. 5) and wave guiding and focusing/defocusing effects caused by refraction over the ocean bathymetry. The latter effects are particularly important near and over the continental shelf and will be further detailed in the next section. Note that similar strong wave guiding and focusing effects were observed during the deep water propagation of recent extreme tsunamis, for the 2004 Indian Ocean tsunami impact in Somalia, which distance-wise was as far from the earthquake source as the far-field areas considered here are from CVV (Fritz and Borrero, 2006), and for the Tohoku 2011 tsunami in Crescent City, which was similarly far away from the source in the Japan Trench (Grilli et al., 2013; Kirby et al., 2013).

Besides these modulations, along the USEC, the figures show first increasing maximum surface elevations towards the coast, due to wave shoaling over the continental slope and shelf break, and then decreasing surface elevations over the wide continental shelf, due to dissipation by bottom friction and, closer to shore, by breaking of the steepest waves; this wave decay will be clearer in results of simulations in the regional grids detailed in the next section.

More specifically, regarding variability of tsunami impact in the farfield, for both flank collapse scenarios, we see: (i) in the east, very large tsunami impact in western Africa and significant impact as well in Portugal; (ii) in the west-southwest, which is the sources' dominant direction, large waves propagating towards south America and the eastern Caribbean islands; (iii) in the northwest, large surface elevations in the Grand Banks, off of Newfoundland, but not closer to shore, likely as a result of significant dissipation from wave breaking and subsequent bottom friction over the shallow shelf; and (iv) in the west, at the scale 
(a)

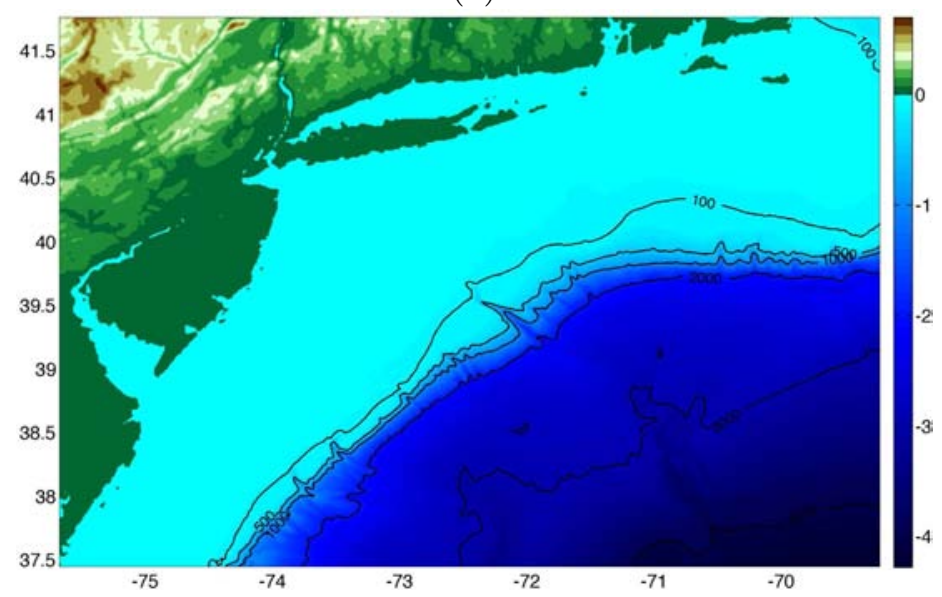

(b)

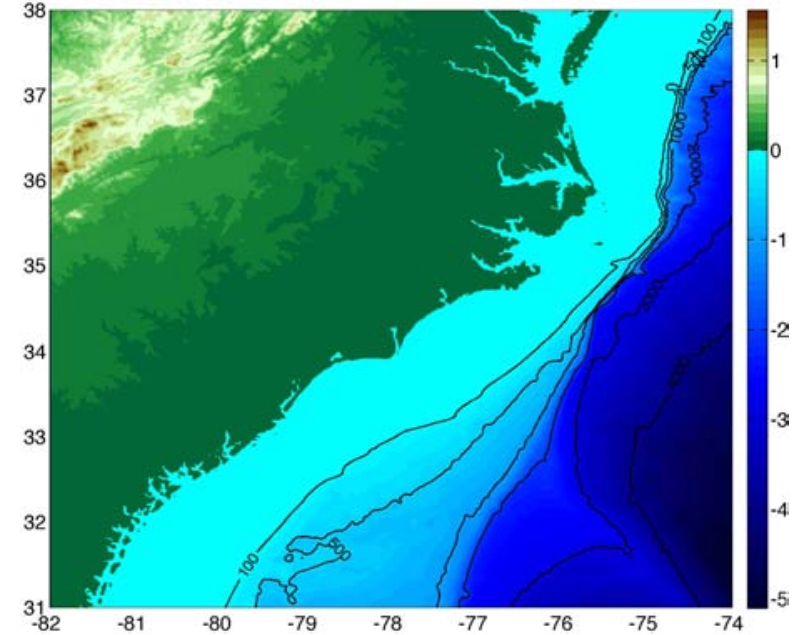

(c)

(d)
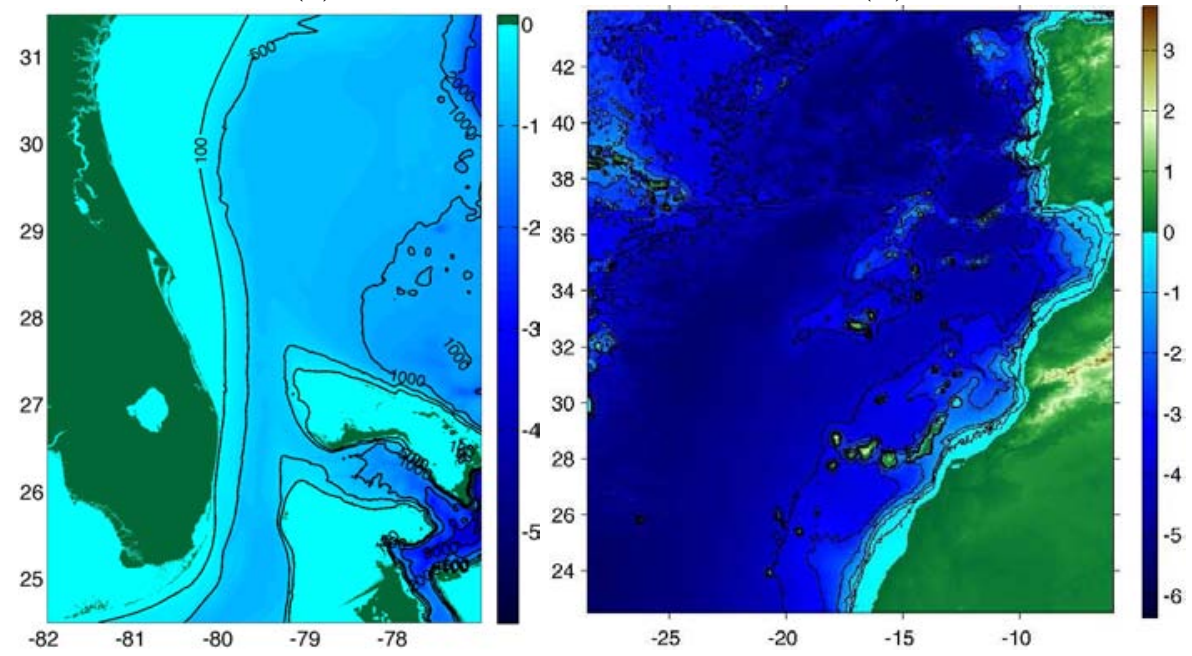

Figure 10. Bathymetry $(<0)$, topography $(>0)$ (color scale in $\mathrm{km}$; contours in meter) in regional grids (see Fig. 4, Table I): (a) N. US reg.; (b) Mid. US reg.; (c) S. US reg.; and (d) W. Africa and W. Europe (bathymetric contours are for the same depth sequence as other grids and are not labeled for clarity). Axes: Long. E. and Long. N. (deg.). 
(a)

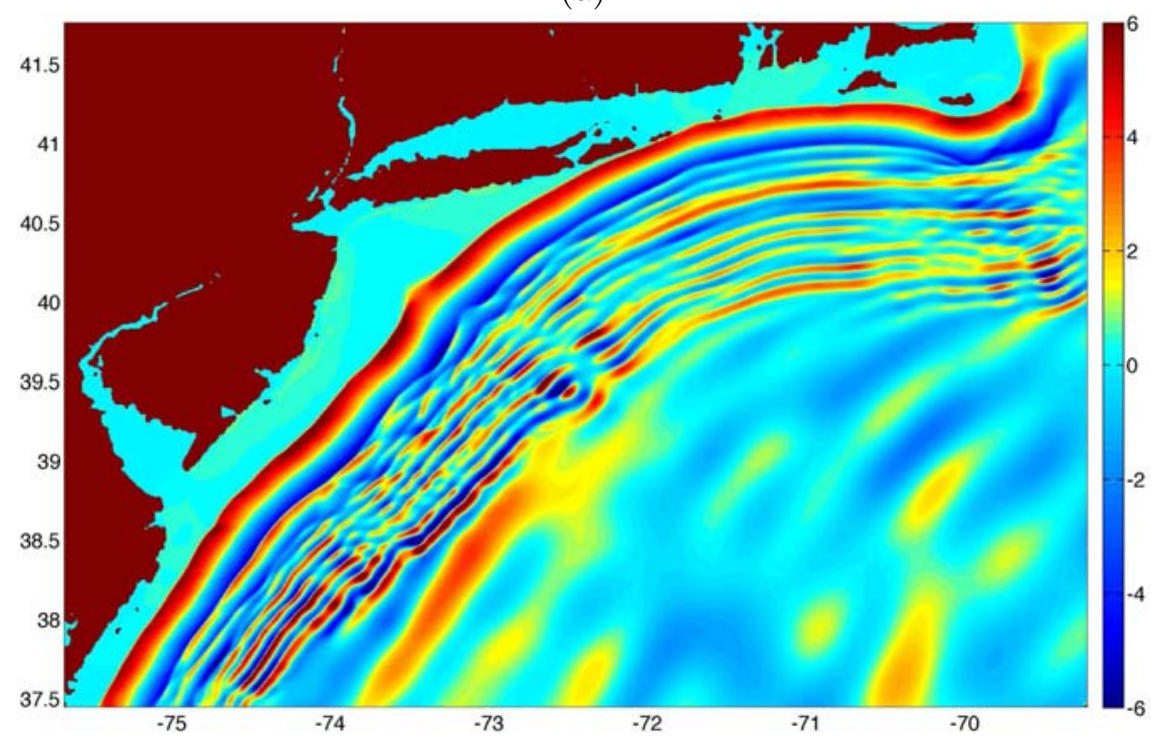

(b)

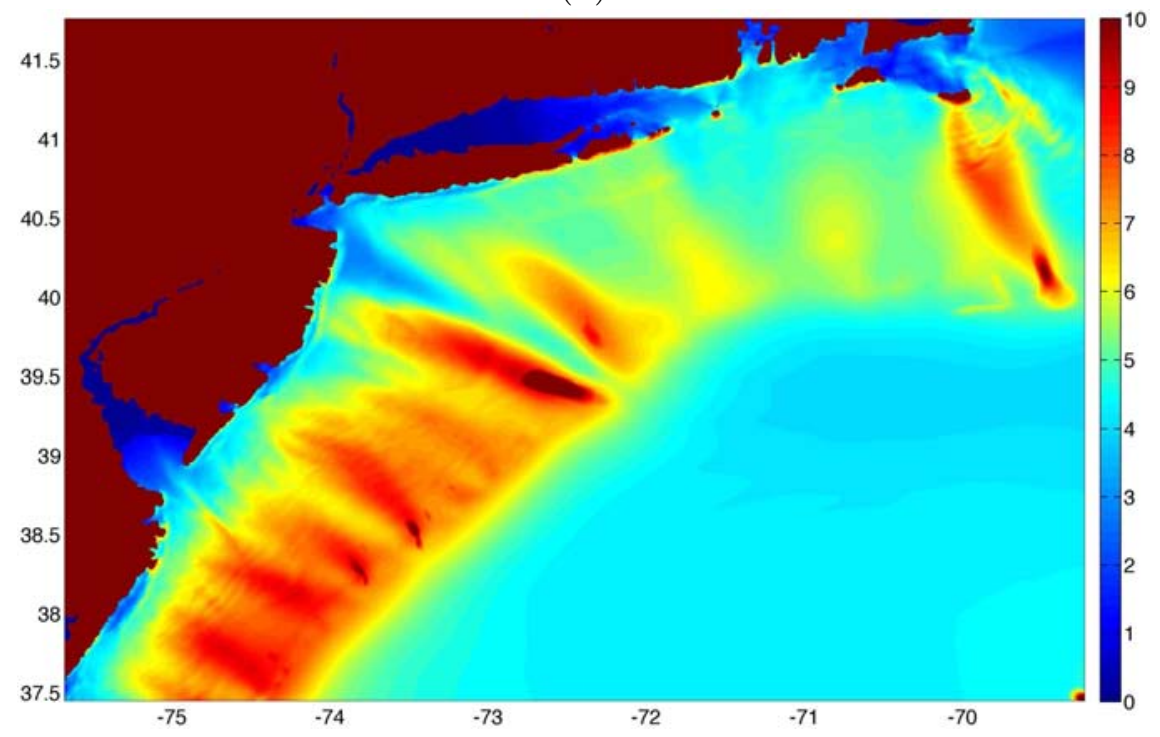

Figure 11. Surface elevation (color scale in meter) computed for the CVV $450 \mathrm{~km}^{3}$ flank collapse scenario, in 20 arc-sec N. US regional grid, off of New Jersey, New York, and Massachusetts (see Fig. 16 for locations of US states): (a) instantaneous elevation at 8h10'; and (b) maximum surface envelope up to 9h30', after the start of the event. Axes are Long. E. (deg.) and Long. N. (deg.). 
of the plots, the largest waves occurring off of Florida, and these waves remaining large all the way to North Carolina.

\section{Far-field tsunami features and coastal impact}

\subsection{INSTANTANEOUS AND MAXIMUM SURFACE ELEVATIONS}

Based on results in the 1 arc-min Atlantic Ocean basin grid, computations were performed by one-way coupling in three 20 arc-sec nested grids covering the entire USEC and one 15 arc-sec nested grid covering the west African and European coasts (Fig. 4, Table I). The bathymetry and topography in these grids is shown in Fig. 10.

Along the USEC, Figure 11a shows the instantaneous surface elevation computed for the extreme CVV $450 \mathrm{~km}^{3}$ flank collapse scenario in the northern regional grid (N. US reg. grid; Table I), at 8h10' into the event, when the long-crested leading elevation wave, more than $5 \mathrm{~m}$ high at most locations, is about to impact (from west to east) Montauk, at the eastern extremity of Long Island, NY, Block Island, RI and the islands of Nantucket and Martha's Vineyard, off of Cape Cod, MA (see Fig. 16 for a definition of state borders along the US east coast and locations of major coastal cities). One can clearly see that the leading and following few wave crest elevations are modulated along-crest, as a result of bathymetric focusing/defocusing (see Fig. 10a). This is clearer in Figure 11b, which shows the envelope of maximum surface elevation computed in this grid up to $9 \mathrm{~h} 10$ '. In this figure, we see a significant alongshore modulation of the maximum surface elevation, as a series of cross-shore stripes, with at the same time a gradual decrease of the wave elevation towards the shore, due to wave breaking and bottom friction dissipations. More specifically, in this figure, waves are being refracted away from the Hudson River Canyon, off of New York City, and as a result concentrate on both northern New Jersey and Western Long Island. Further east, as observed before, surface elevations are larger off of Montauk and Nantucket, due to underwater ridges. To the south, focusing also occurs towards Atlantic City and Cape May, NJ.

Figures 12 and 13 show similar results for the middle and southern regional grids (Mid. and S. US reg. grids; Fig. 4, Table I), respectively. In both grids, the incoming tsunami wave train also has a large leading long-crested elevation wave, followed by a train of several large waves. As before, the maximum surface elevation of the leading wave is significantly modulated along shore but slightly less so off of the Chesapeake Bay. Overall, there is significant wave focusing towards the outer banks (Cape Hatteras; around 35.5 deg. N Lat.) and the Cape Fear area 
(a)

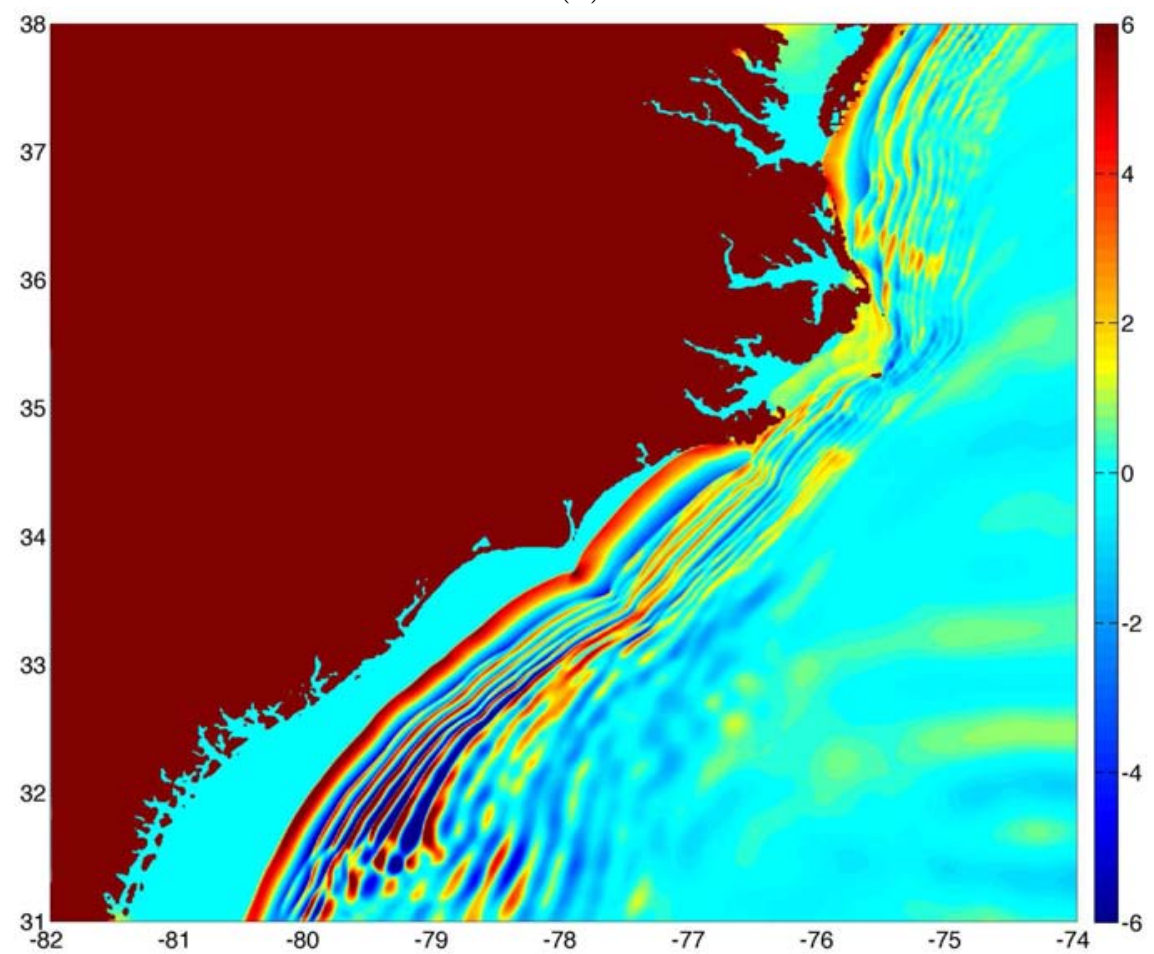

(b)

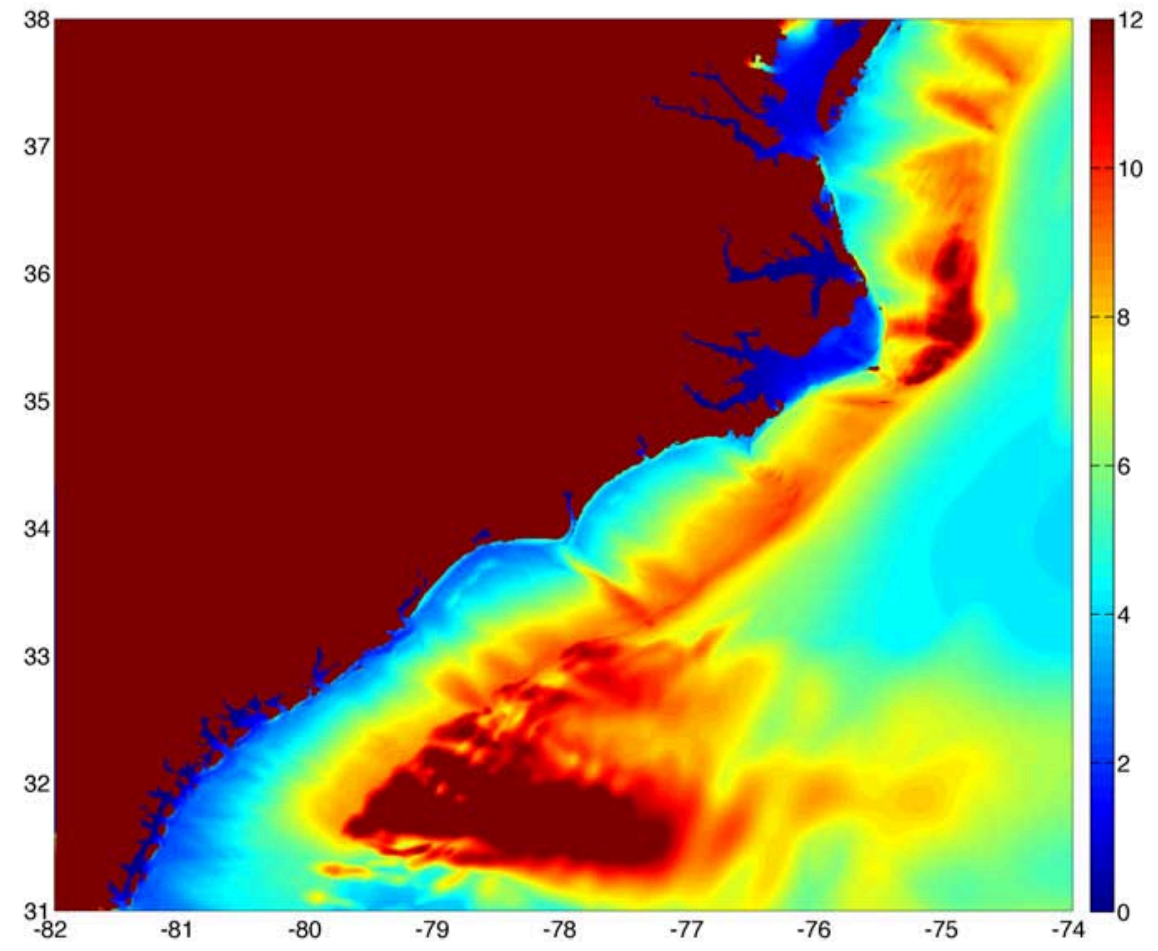

Figure 12. Surface elevation (color scale in meter) computed for the CVV $450 \mathrm{~km}^{3}$ flank collapse scenario, in 20 arc-sec Mid US regional grid, off of South/North Carolina, Virginia, Maryland and Delaware (see Fig. 16 for locations of US states): (a) instantaneous elevation at 8h55'; and (b) maximum surface envelope up to $10 \mathrm{~h} 40$ ', after the start of the event. Axes are Long. E. (deg.) and Long. N. (deg.). 
(a)

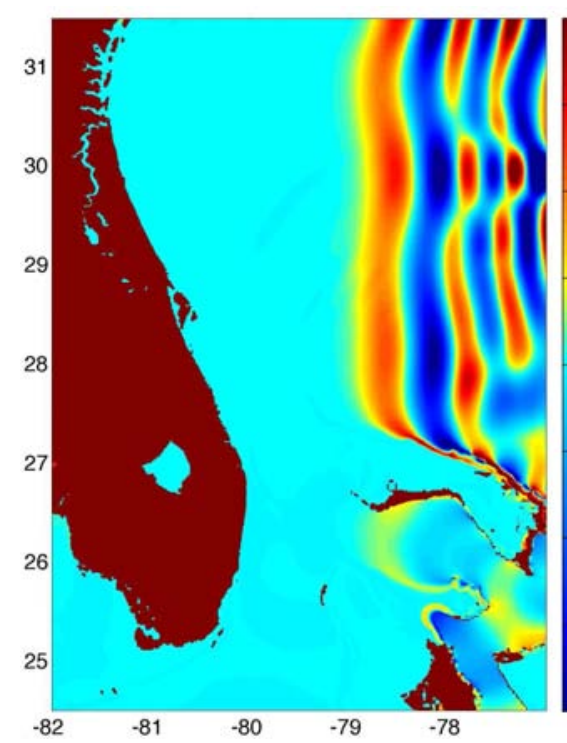

(c)

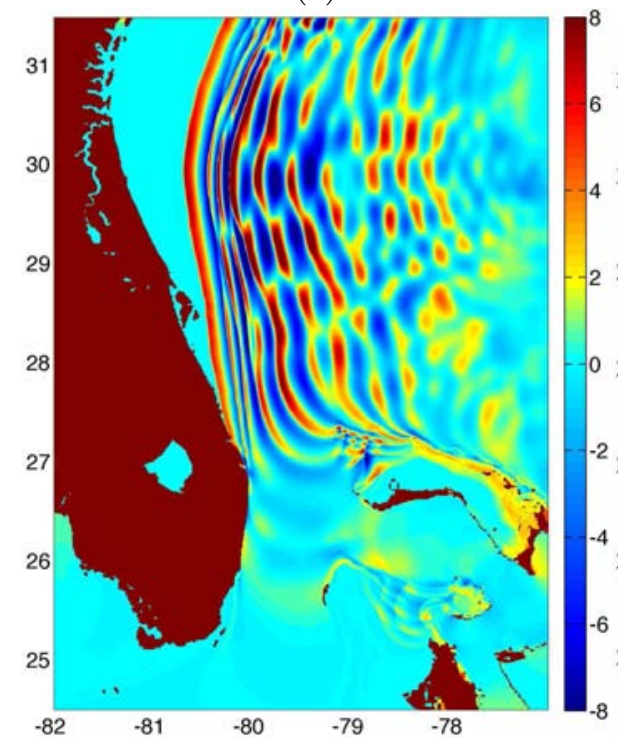

(b)

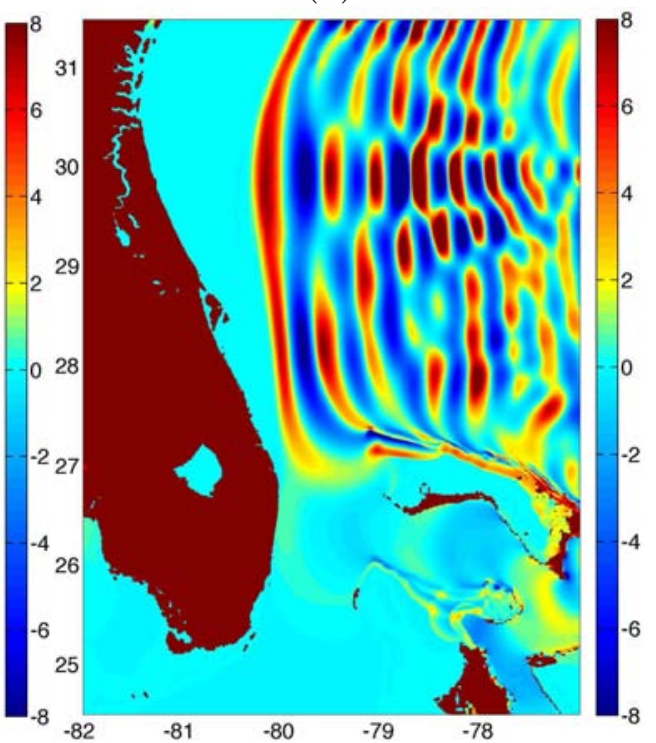

(d)

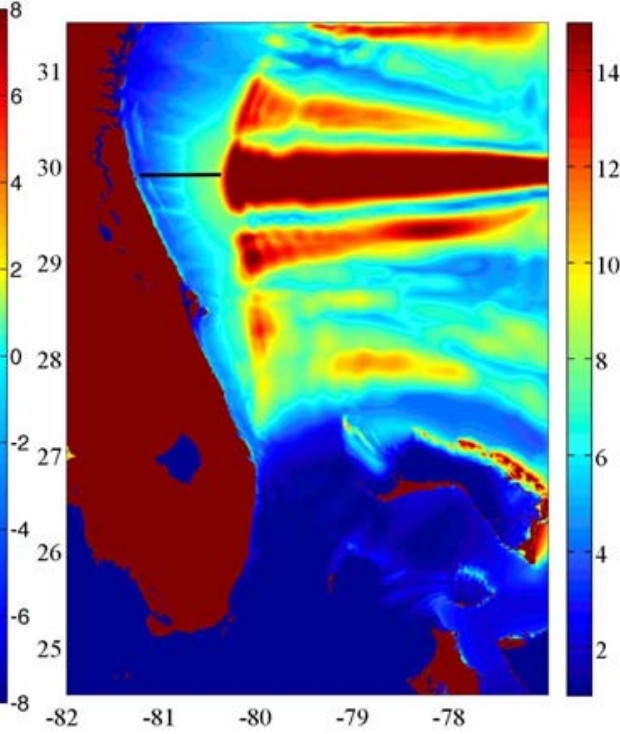

Figure 13. Surface elevation (color scale in meter) computed for the CVV $450 \mathrm{~km}^{3}$ flank collapse scenario, in 20 arc-sec S. US regional grid, off of Florida (see Fig. 16 for locations of US states): (a) instantaneous elevation at 7h55'; (b) instantaneous elevation at $8 \mathrm{~h} 25$ '; (c) instantaneous elevation at 8h55'; and (d) maximum surface envelope up to 10h40', after the start of the event; the black line marks a cross-shore transect where dissipation is analyzed in more detail in Fig. 14. Axes are Long. E. (deg.) and Long. N. (deg.). 

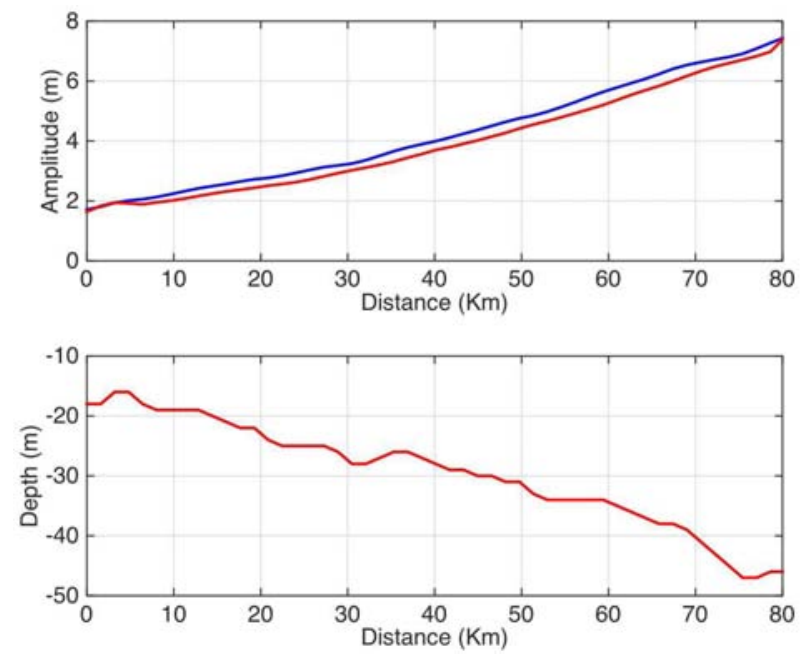

Figure 14. Analysis of dissipation and surface elevation decay along the transect marked in Fig. 13d, as a function of distance from shore: (a) Comparison between surface elevation computed in FUNWAVE-TVD (red) and predictions of Dean and Dalrymple's (1991) analytical formula (blue) - the initial offshore wave elevation is FUNWAVE's value for both cases. (b) Depth variation along the transect.

(near Wilmington around 34 deg. N Lat.) in North Carolina, and off of south Carolina (south of Charlestown; around 32 deg. N Lat.). Off of Florida, Fig. 13 shows a very strong alongshore modulation of the maximum surface elevations, with these being largest off of Orlando to Jacksonville (around $30 \mathrm{~N}$ Lat.). There is again in all cases a strong decay of surface elevations toward shore, as a result of large energy dissipation over the wide shelf.

To confirm that the model prediction of large dissipation over the shelf, seen in many instances of the above results, is physical and not a result of numerical dissipation, we compared model results in a crossshore transect off of Florida (Fig.13d), where the incident offshore waves exceed $10 \mathrm{~m}$, to an analytical formula predicting the decay of wave amplitude $a$ due to bottom friction over the actual bathymetry of a transect (Dean and Dalrymple, 1991). This formula expresses the dissipation $\epsilon_{D}$ of energy flux, $E_{f}=E c_{g}$, by bottom friction (with $E=(1 / 2) \rho g a^{2}$ the wave energy and $c_{g}$ the group velocity), as a function of the cross-shelf distance $x$, i.e.,

$$
\frac{\mathrm{d} E_{f}}{\mathrm{~d} x}=-\epsilon_{D} \quad \text { with } \quad \epsilon_{D}=\frac{\rho f}{6 \pi} u_{b m}^{3}=\frac{\rho f}{6 \pi}\left(\frac{a \omega}{\sinh k h}\right)^{3}
$$

where $\rho$ is water density, $g$ the gravitational acceleration, $k$ is the wavenumber, $\omega$ the wave angular frequency, and $u_{b m}$ denotes the max- 
(a)

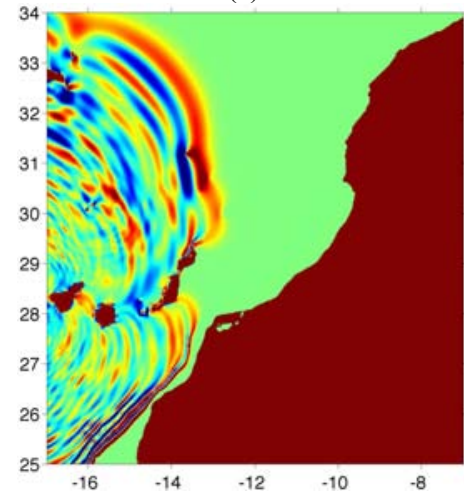

(c)

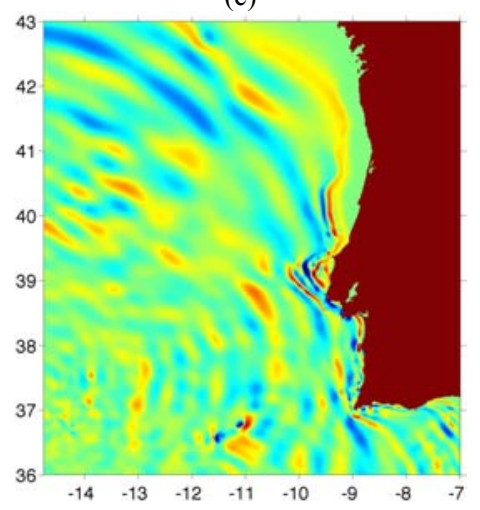

(d) (b)

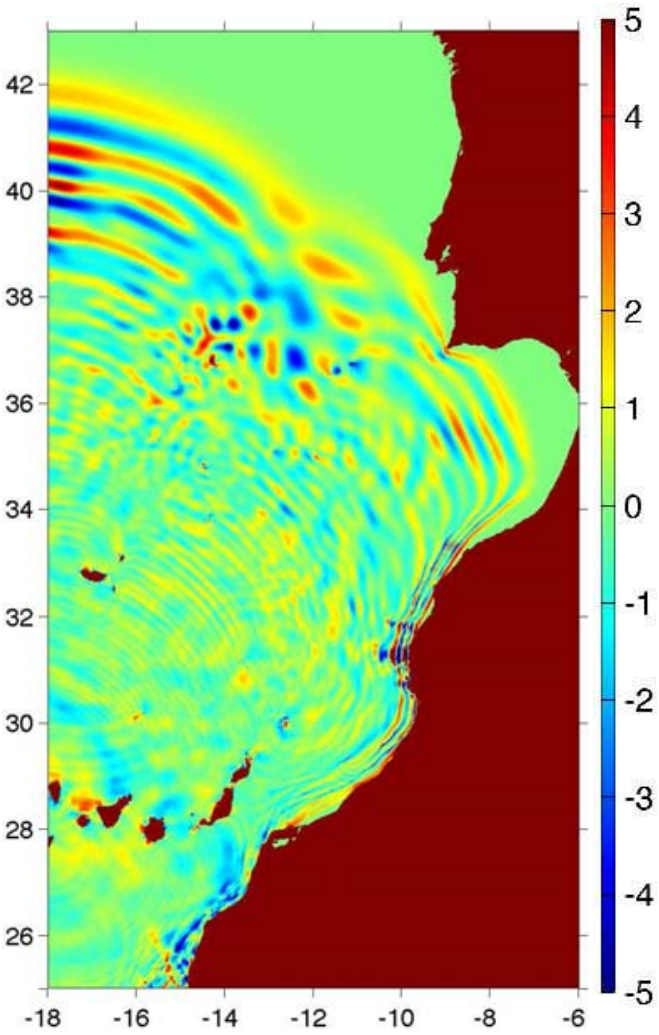

(e)
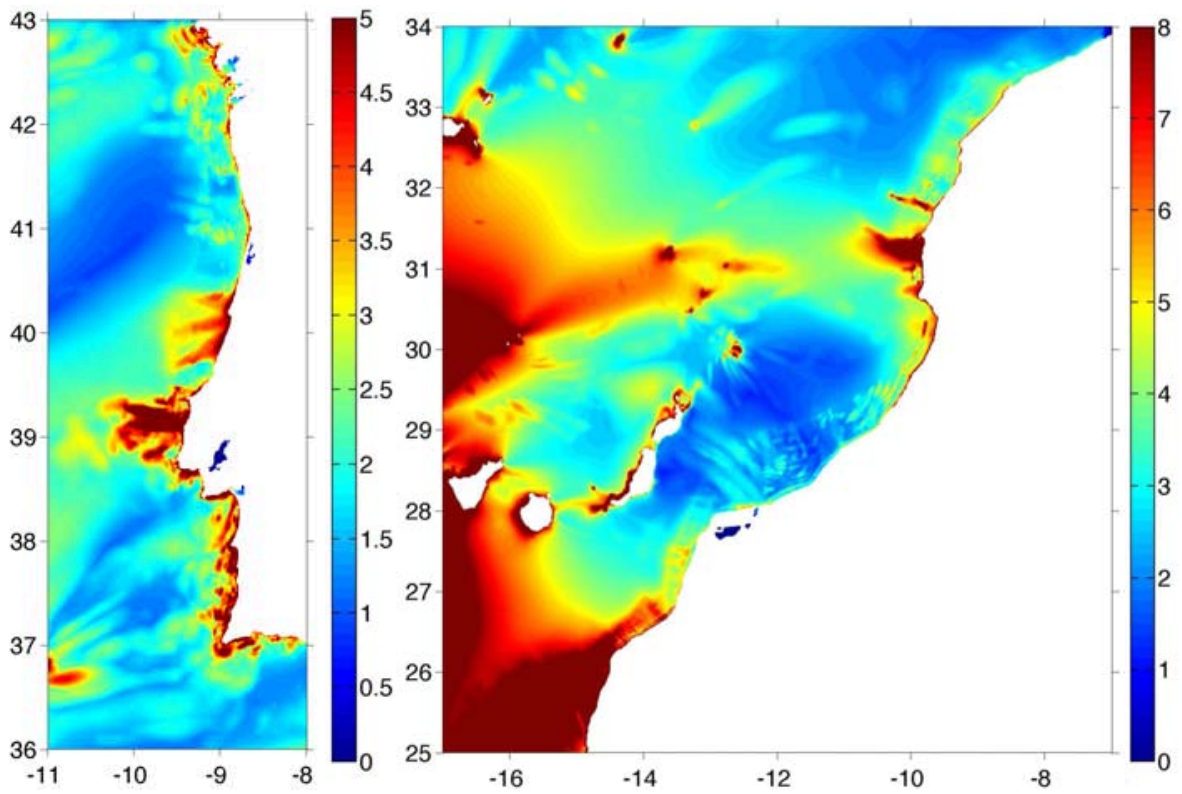

Figure 15. Surface elevation (color scale in meter) computed for the CVV $80 \mathrm{~km}^{3}$ flank collapse scenario, in 15 arc-sec regional grid, off of western Africa and western Europe (Fig. 4, Table I). Instantaneous elevation at : (a) 1h20'; (b) 2h20'; and (d) 2h50'. Maximum surface envelope, up to $4 \mathrm{~h}$ (d,e). Axes are Long. E. (deg.) and Long. N. (deg.). 
imum horizontal velocity on the bottom. Assuming linear long waves (i.e., $c=\omega / k \simeq \sqrt{g h}$ and $\sinh k h \simeq k h$ ), and $f=8 C_{d}$, which corresponds to FUNWAVE-TVD's parameterization of bottom friction, we derive the following equation,

$$
\frac{\mathrm{d} a}{\mathrm{~d} x}=-\frac{4 C_{d}}{3 \pi}\left(\frac{a}{h}\right)^{2}+\frac{a}{4|h|} \frac{\mathrm{d} h}{\mathrm{~d} x}
$$

The latter formula predicts the wave amplitude $a(x)$ across a onedimensional transect of bathymetry $h(x)(<0)$ and has two terms in its right-hand-side, the first one represents bottom friction dissipation effects and the second one predicts amplitude changes due to shoaling over a varying depth. To apply the formula, we specified the initial wave elevation at the edge of the shelf based on FUNWAVETVD's results. Fig. 14 compares results of applying this formula to those of FUNWAVE-TVD. A good agreement is observed between both. Moreover, we verified that over most of this transect, the wave height over depth ratio does not reach the breaking limit (set here to $H / h=0.8$ ). Hence, bottom friction is the only source of energy dissipation in this cross-section. Because of the agreement between the numerical results and the analytical prediction, we conclude that the model is behaving properly over the continental shelf, and that the large decay in wave elevation is caused by bottom friction rather than numerical dissipation.

Fig. 15 shows the tsunami impact caused by the $80 \mathrm{~km}^{3}$ scenario in western Europe and western Africa, computed in the 15 arc-sec regional grid (W. Europe and W. Africa grid; Fig. 4, Table I). Figs. 15a-c show instantaneous surface elevations computed at 1h20', 2h20' and 2h50' into the event. The first two snapshots are for the same times as in Figs. 6 a,b for the $450 \mathrm{~km}^{3}$ scenario in the 1 arc-min grid; we see that wave patterns and phases appear to be similar, although wave amplitudes are smaller by a factor of 2.5 to 3 . After $1 \mathrm{~h} 20$ ', the tsunami is about to impact the coast of western Africa with over $10 \mathrm{~m}$ high waves (trough to crest). After 2h20', $6 \mathrm{~m}$ high waves are reaching the SW tip of the western European coast and $4 \mathrm{~m}$ high waves are about to enter the Strait of Gibraltar. After 2h50' waves of 8-10 m height are starting to impact the Lisbon area (38.7 deg. N Lat.) and are approaching Coimbra (40.15 deg. N Lat.), north of it. Figs 15d,e show envelopes of maximum surface elevations computed along the western European and African coasts, respectively, up to $4 \mathrm{~h}$ of simulations. As for the USEC, we see a very strong alongshore modulation of the maximum surface elevations, again due both to the source directionality and bathymetric wave focusing/defocusing. In Europe, although much of the tsunami energy is directed away from the continent (Fig. 9 and Fig. 15b), Fig. 
$15 \mathrm{~d}$ shows that, even for the more moderate $80 \mathrm{~km}^{3}$ scenario, there is substantial tsunami impact along the Portuguese coastline, particularly in and around Lisbon and Coimbra. Fig. 15e finally shows that, as could be expected from its proximity to La Palma, very large waves would impact the northwest African coast. Maximum surface elevations along the coast reach over $10 \mathrm{~m}$ in the western Sahara in Morocco (25-27 deg. $\mathrm{N}$ lat.) and further north between Agadir and west of Marrakech (30.5-31.5 deg. N Lat.).

\subsection{MAXIMUM COASTAL IMPACT AND INUNDATION MAPPING IN EASTERN US}

As part of work done for NTHMP, the authors have been developing high-resolution tsunami inundation maps for the most critical or exposed areas of the USEC, by way of numerical simulations. These maps represent envelopes of maximum inundation caused by extreme nearand far-field tsunami sources in the Atlantic Ocean basin. The CVV 80 and $450 \mathrm{~km}^{3}$ flank collapse scenarios presented here are two of the sources considered in this NTHMP work. Initial inundation mapping efforts were based on the latter, most extreme CVV scenario, but more recently, in view of its likely very long return period as compared to other sources, it was decided in coordination with NTHMP leadership to base the USEC inundation mapping on the former ECWCS. Other tsunami hazard assessment work, however, performed for critical coastal infrastructures such as power plants still considered the very conservative $450 \mathrm{~km}^{3}$ scenario.

Results of simulations discussed above indicate that a tsunami from the $450 \mathrm{~km}^{3}$ source would significantly impact the entire US east coast and, particularly, the mid-Atlantic states and northern Florida. However, impact of a tsunami from the smaller $80 \mathrm{~km}^{3}$ scenario would also be quite large in many locations. Fig. 16 compares maximum tsunami elevation simulated for these two scenarios, along a $5 \mathrm{~m}$ depth contour parallel to the USEC (plotted as a function of the distance calculated along the contour, from south to north); limits of the various US states are marked on both the contour and the surface elevation plot. In general, surface elevations computed for the most extreme 450 $\mathrm{km}^{3}$ scenario are about 2.5-3 times larger than those for the $80 \mathrm{~km}^{3}$ ECWCS. However, as expected from earlier results, for both scenario, we observe a closely similar, and fairly significant, alongshore variation of the maximum surface elevation. This is due in part to the directionality of the CVV tsunami sources (Figs. 3 and Fig. 9), but mostly to focusing and de-focusing of wave energy flux caused by refraction over the nearshore bathymetry (e.g., succession of canyons and ridges). 
(a)

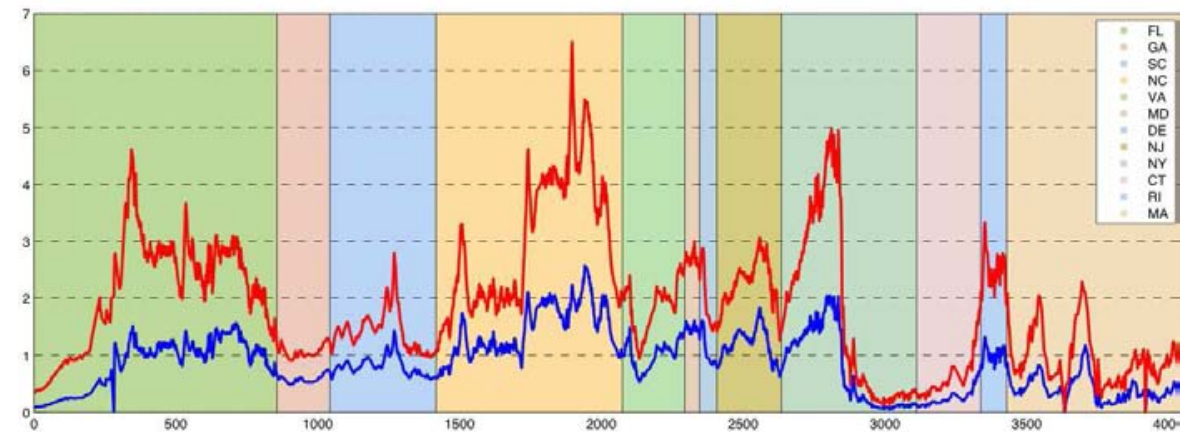

(b)

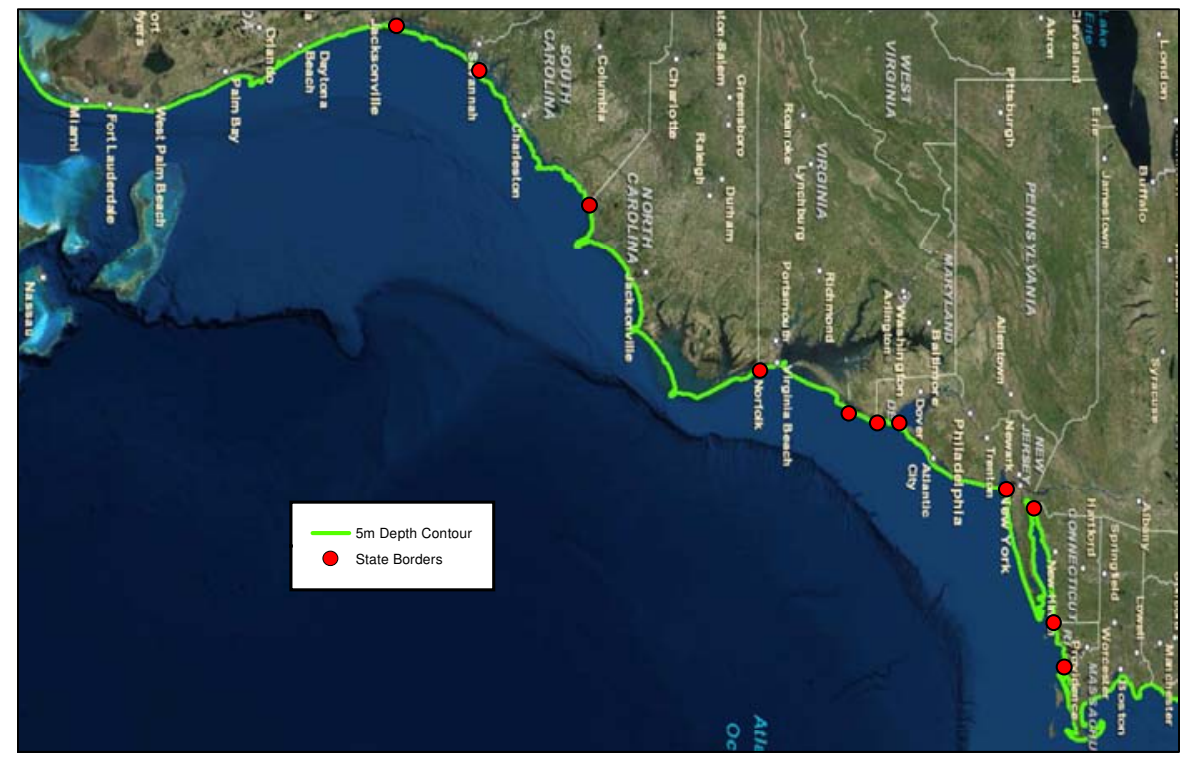

Figure 16. (a) Transects of maximum surface elevation (meter) computed for the 80 $\mathrm{km}^{3}$ (blue) and $450 \mathrm{~km}^{3}$ (red) scenarios, along a $5 \mathrm{~m}$ depth contour parallel to the US eastern coastline (show in (b)), as a function of the distance calculated along the contour $(\mathrm{km})$, from south to north. Limits of the various US states are marked on both the transect (a) and the coastline (in (b)).

This important feature of wave propagation over the wide USEC shelf is further discussed below. As also seen in previous results, maximum tsunami impact occurs around the mid-Atlantic states, particularly in North Carolina, but also in New York and Florida. Looking at maximum surface elevations computed for the $450 \mathrm{~km}^{3}$ scenario, we see that, compared to the incident time series of surface elevations plotted at the $200 \mathrm{~m}$ bathymetric contour in Fig. 8, these have significantly decreased 
over the wide continental shelf, due essentially to bottom friction (see Fig. 14) and some local effects of wave breaking dissipations. This wave elevation decay towards the shore was apparent in plots of maximum envelopes of surface elevations detailed above (Figs. 11b, 12b and 13d).

To better analyze the controlling effect of the wide shelf bathymetry on coastal tsunami propagation and impact, we performed a ray-tracing analysis from the CVV source to the USEC, by solving the geometric optic eikonal equation with a fast-marching algorithm. Results of this simplified analysis, which neglects wave diffraction, reflection and energy dissipation, are plotted in Figs. 17a to c (note that for clarity, only $1 \%$ of the computed wave rays was plotted). These figures clearly show how incident long waves start refracting in great depth and gradually bend over the shelf in a manner that the rays eventually become nearly orthogonal to the nearshore bathymetry. In doing so, areas of ray convergence occur over submarine ridges (or equivalent) and ray divergence over submarine canyons, that closely match the patterns of low and high values of coastal tsunami surface elevation observed in Fig. 16. This is because where ray convergence occurs, the wave energy flux density increases, leading to increased surface elevations, whereas where ray divergence occurs, it is the opposite. For instance, in Fig. 17a we see that, due to the Hudson River Canyon V-shaped bathymetry, tsunami wave rays refract towards the northern parts of New Jersey and the western half of Long Island, NY. Thus, this bathymetric feature mitigates tsunami impact on New York harbor. A similar behavior is observed in Fig. 17a over the Delaware Bay Canyon, where tsunami wave rays refract towards Atlantic City, NJ in the north and Ocean City, MD in the south. Figs. 17b and c show similar results for areas further south along the USEC.

We expect these wave ray patterns to be closely related to the alongshore variation of maximum surface elevation shown in Fig. 16, particularly in areas where energy dissipation over the shelf is not too large. This was verified (and quantified) two ways for the CVV $450 \mathrm{~km}^{3}$ scenario, along the $5 \mathrm{~m}$ depth contour: (i) in Fig. 17d, we compare the normalized number of wave rays that intersect a circle of given radius (here we used a $0.1^{\circ}$ radius or about $10 \mathrm{~km}$ ), at many equally spaced locations, versus the normalized surface elevation computed from Fig. 16; and (ii) in Fig. 17e, we compare the surface elevation computed based on wave rays with the method of Bouws and Battjes (1982), to the surface elevation computed from Fig. 16; this method is based on conservation of energy flux between the rays initial and end points. The alongshore variation of the two different metrics based on wave rays is in general in reasonable agreement with the surface elevations computed with FUNWAVE-TVD, but more particularly so north of New Jersey, in 
(a)

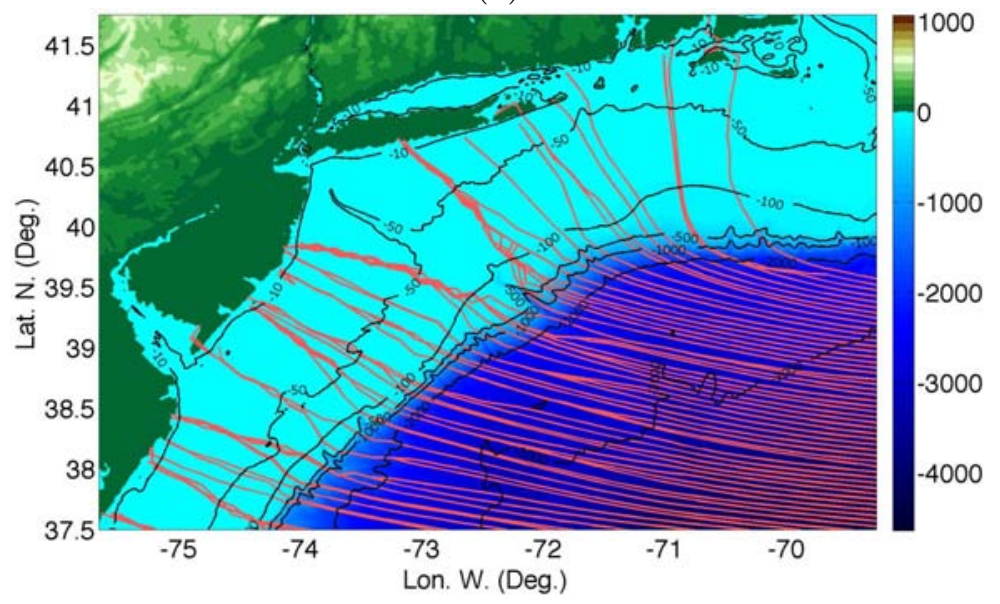

(b)

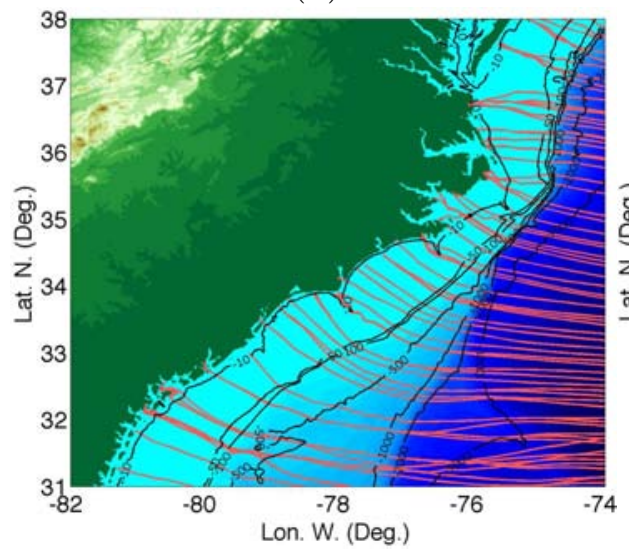

(c)

(d)

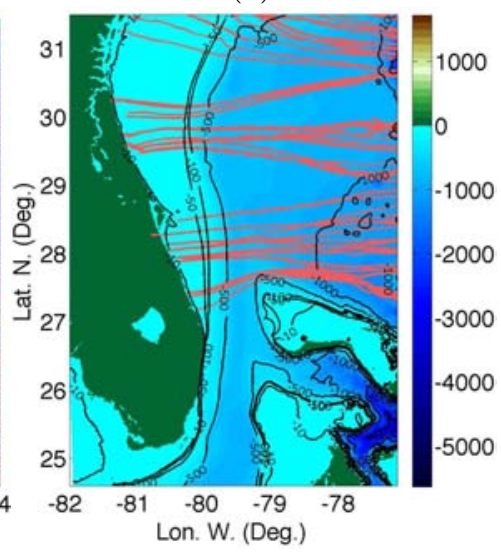

(

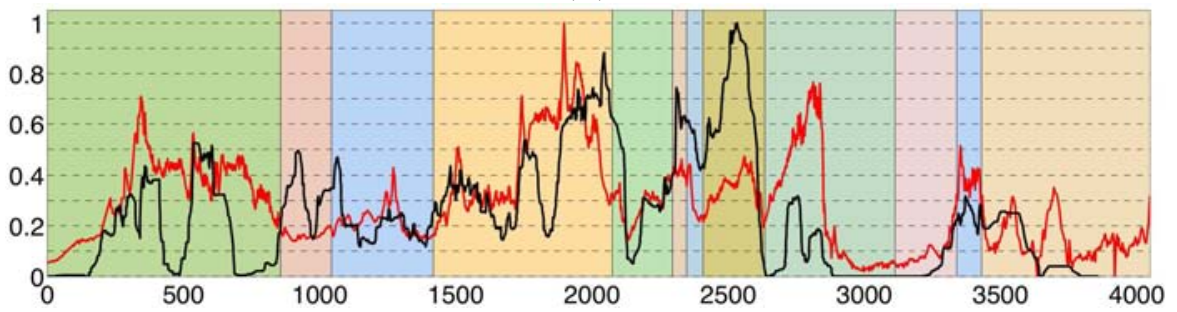

(e)

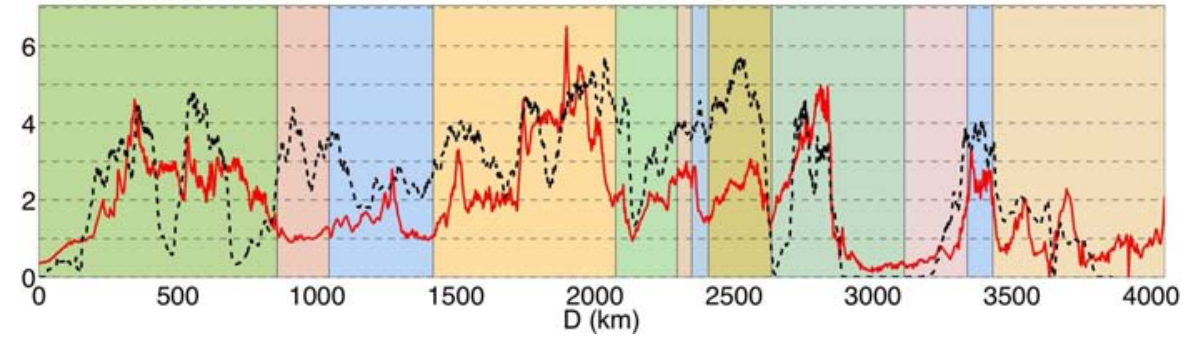

Figure 17. (a-c) Wave rays (solid red) computed for long waves propagating in the Atlantic Ocean, from the CVV to the USEC (color scale and contours are bathymetry/topography in meter); the three panels correspond to grid areas from Fig. 10. (d,e) (solid red) maximum surface elevation for the CVV $450 \mathrm{~km}^{3}$ scenario along the $5 \mathrm{~m}$ depth contour from Fig. 16 (see this figure for the definition of each state's color code): (d) normalized by maximum value, (e) in meter; and (solid black) ray concentration (dashed black) wave height obtained from rays, following Bouws and Battjes (1982). 
south FLorida and the Corolinas (except around Cape Hatteras, NC), where we see a higher correlation. In other areas, although the trend is reasonably well predicted by the ray analysis, wave heights are typically overestimated due to neglecting dissipation from bottom friction and breaking. Nevertheless, these results confirm the controlling effect of a wide continental shelf, and of the refraction it induces on incoming tsunamis, for surface elevations at the coast.

Finally, because long wave refraction patterns are only bathymetry (and not frequency) dependent, any incoming tsunami should refract in a similar manner, once close enough to shore, in shallow enough water. Hence tsunamis caused by different CVV flank collapse mechanisms or volumes should have similar nearshore areas of ray convergence or divergence, and thus enhanced or reduced wave elevation, whatever their incidence angle. This is supported by the similar alongshore variations of the maximum surface elevations shown in Fig. 16 for the CVV 80 and $450 \mathrm{~km}^{3}$ scenarios.

In the mid-Atlantic region, as is apparent on Fig. 18, the resort town of Ocean City, MD (at the southern limit of DE on Fig. 16), is particularly vulnerable to coastal flooding, from both hurricanes and potentially tsunamis, because it is made of heavily developed lowelevation barrier beaches and islands, which also pose significant evacuation problems. Although this aspect of our work will not be detailed here, Fig. 19 shows an example of a high-resolution tsunami inundation map prepared for Ocean City based on the CVV $450 \mathrm{~km}^{3}$ extreme flank collapse scenario, which could be used for emergency management purpose. This map shows the extent of the flooded area and the maximum penetration of the tsunami, computed in a $10 \mathrm{~m}$ resolution grid based on results of the 20 arc-sec Mid US regional grid (Fig. 12), by one-way coupling in a series of additional nested grids with 4 arc-sec $(125 \mathrm{~m})$, $30 \mathrm{~m}$ and $10 \mathrm{~m}$ resolution, shown in Fig. 20. Other flow parameters such as maximum velocity and vorticity, and momentum flux based on flow depth, can be similarly plotted and used for estimating tsunami effects on navigation, coastal erosion, and forces on structures.

\section{Conclusions}

We simulated tsunami generation, propagation, and far-field impact in the Atlantic Ocean Basin, for two extreme flank collapse scenarios of the Cumbre Vieja Volcano (CVV) in La Palma (Canary Islands), defined by Abadie et al. (2012): (i) the ECWCS (based on a slope stability analysis), with a $80 \mathrm{~km}^{3}$ volume; and (ii) the most extreme scenario with a $450 \mathrm{~km}^{3}$ volume. Both of these scenarios can be qualified as 


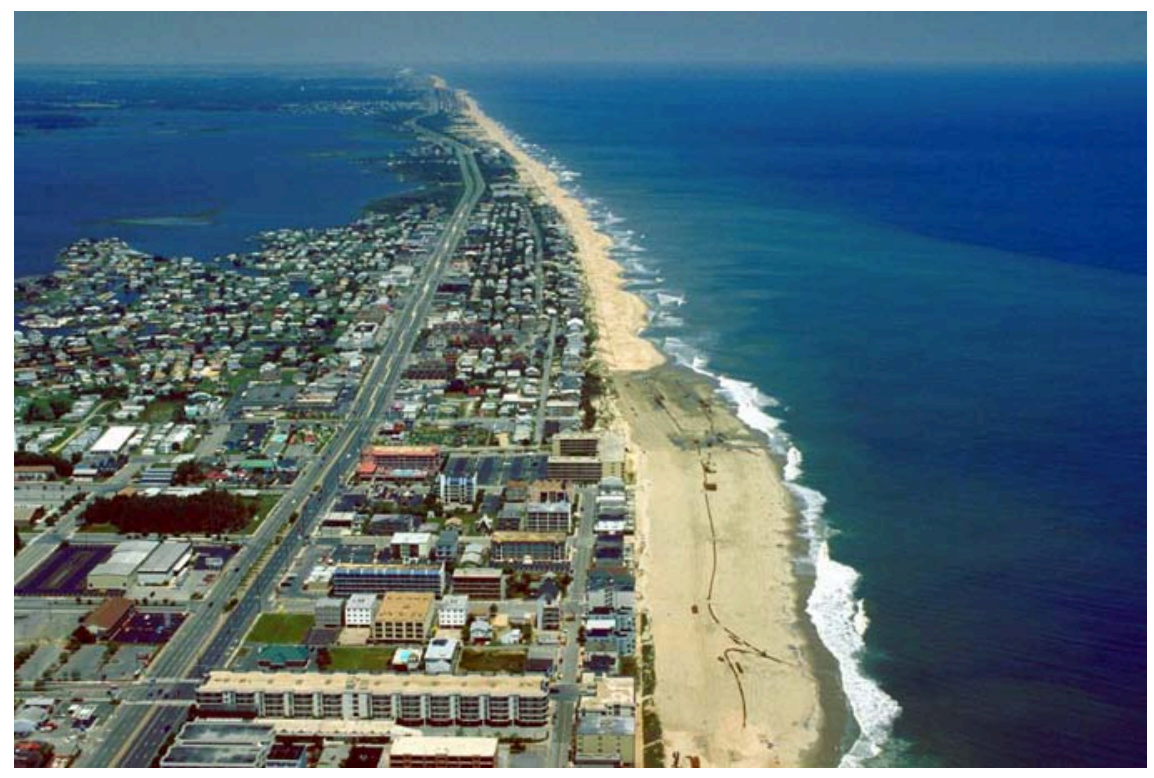

Figure 18. Aerial view of Ocean City, MD, illustrating the vulnerability to inundation of the heavily developed barrier island.

being very conservative and although their return period is unknown, earlier geological studies indicate that massive CVV flank collapses are associated with return periods of $\mathcal{O}(100,000)$ years.

For each scenario, slide motion and the resulting initial tsunami generation were computed by Abadie et al. (2012) using THETIS, a 3D multi-fluid Navier-Stokes model with a VOF interface tracking; the motion of the subaerial slide material was modeled as a heavy, nearly inviscid, fluid with a density similar to that of basalt. At 5 min into the event, when the energy from the slide has been transferred to the water motion, the wave elevation and velocity for the generated tsunami are used to initialize FUNWAVE-TVD, a 2D (horizontal) fully nonlinear Boussinesq long wave model with extended dispersion properties, to continue simulating their propagation in the near-field, around Canary islands, in a $500 \mathrm{~m}$ resolution Cartesian grid. Then, at $20 \mathrm{~min}$ into the event, surface elevation and velocity computed in this grid are again specified as initial condition for a 1 arc-min Atlantic Ocean Basin grid, to compute the transoceanic tsunami propagation and far-field impact. Coastal tsunami impact in the far-field is finally computed by one-way coupling in a series of finer regional nested grids, with 15-20 arc-sec resolution and, in some areas of the USEC, in additional Cartesian nested grids down to a $10 \mathrm{~m}$ resolution. Details of the selection of slide scenarios, modeling of 3D slide motion and tsunami source generation 


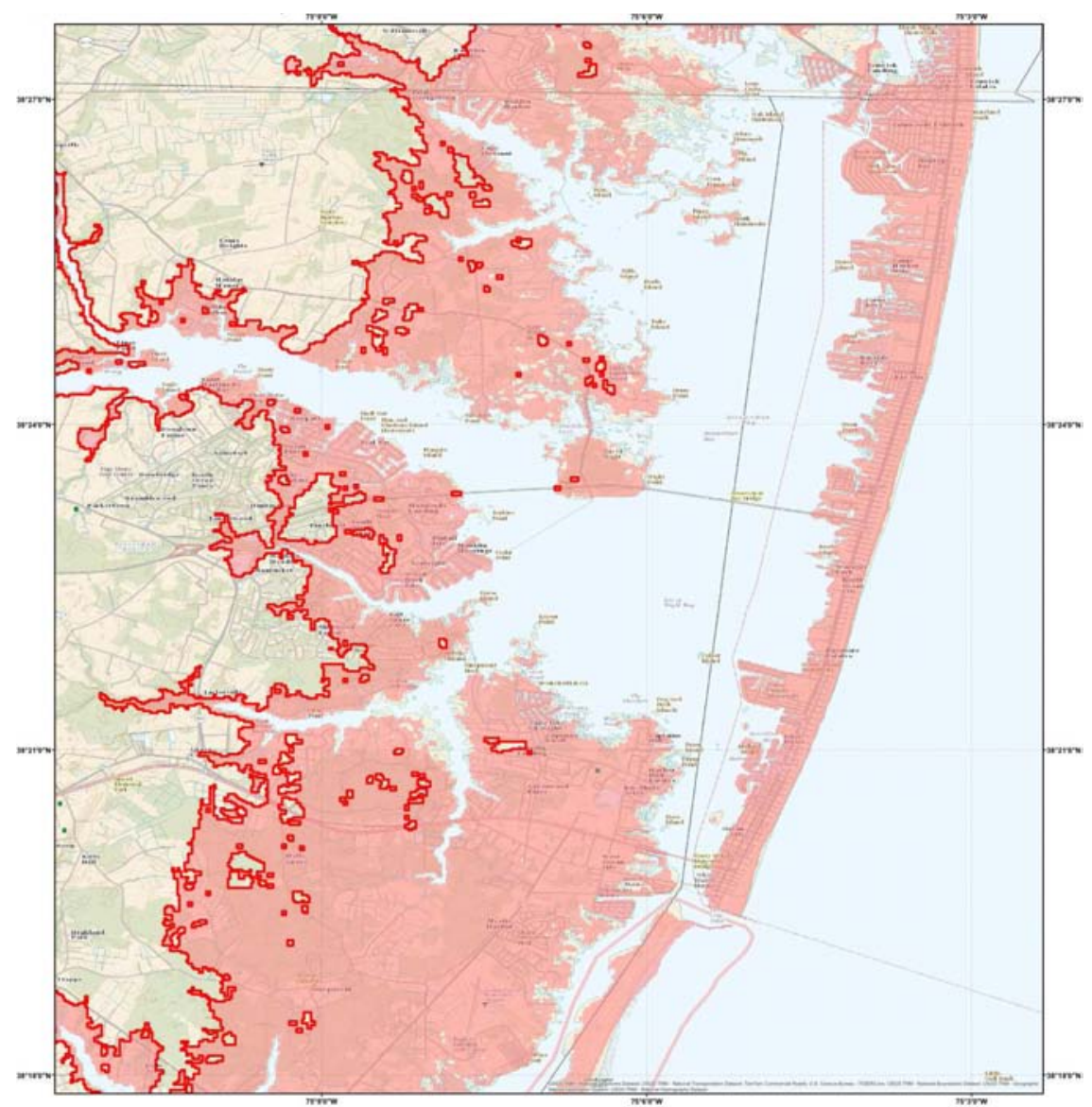

Figure 19. Tsunami inundation map (10 m resolution grid) for the $450 \mathrm{~km}^{3} \mathrm{CVV}$ flank collapse case (Abadie et al., 2012): inundation limit (thick red line); inundated area (pink area).

with THETIS, and analysis of results around La Palma and in the near-field can be found in Abadie et al. (2012).

Our overall findings regarding near- and far-field wave generation are qualitatively consistent with earlier results (Gisler et al., 2006; Løvholt et al., 2008), but near-field waves computed in this study appear to be notably higher than in these earlier works and attenuation rates during their transoceanic propagation smaller. In the far-field, the generated tsunamis appear to be made of wave trains of 3 to 5 significantly large (long-crested) waves of 9 to 12 min period. This pattern confirms the importance of using a dispersive long wave model such as FUNWAVE-TVD to simulate landslide generated waves, which have 


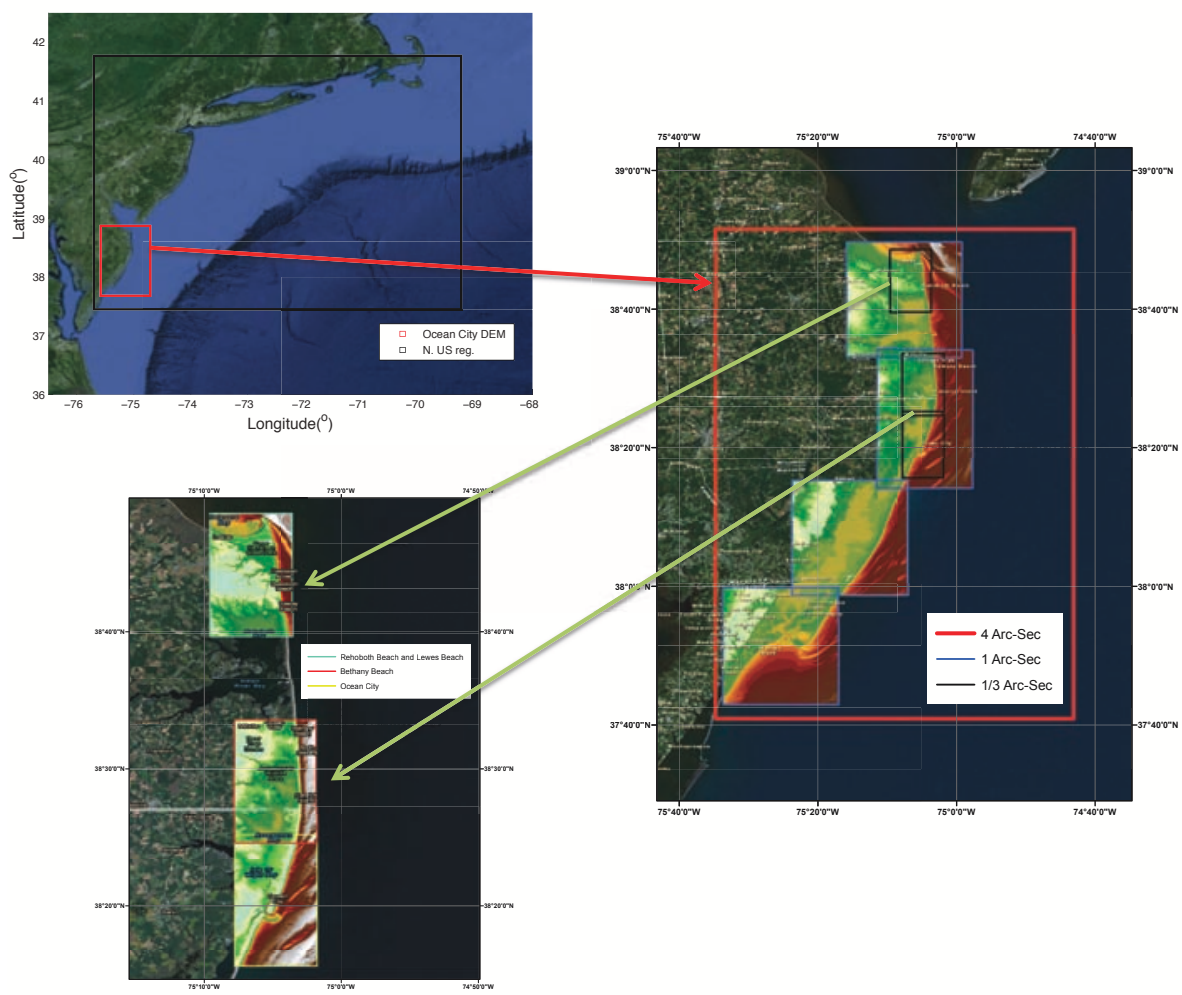

Figure 20. Nested FUNWAVE-TVD grids used for developing high-resolution inundation maps for the Ocean City, MD area. N. US reg. grid (20 arc-sec resolution) is forced along its boundary by the far-field tsunami sources simulated in the 1 arc-min ocean basin grid (Fig. 4). The red box marks the boundary of the "Ocean City DEM" 4 arc-sec (about $125 \mathrm{~m}$ ) resolution grid. OC- 1 to OCE- 4 are 1 arc-sec (about $30 \mathrm{~m}$ ) resolution grids nested within this grid, and a few finer $1 / 3$ arc-sec (about $10 \mathrm{~m}$ ) resolution grids are nested within those, in areas of greatest interest.

relatively shorter wavelengths than coseismic tsunamis; this conclusion was also reached in a number of earlier landslide tsunami studies by these and other authors (see earlier discussions in the paper).

Along the US east coast, for the most extreme CVV scenario, while wave heights at the $200 \mathrm{~m}$ isobath are in the $10-20 \mathrm{~m}$ range (troughto-crest), because of significant decrease in wave height due to energy dissipation over the wide shelf, the maximum nearshore surface elevations along the coast (at the $5 \mathrm{~m}$ isobath) become significantly less, in the 1-6 $\mathrm{m}$ range, and less than $3 \mathrm{~m}$ at most locations, except in a few areas, such as off of West Palm Beach (FL), Cape Hatteras and the outer Banks (NC), and Ocean City (MD). For the $80 \mathrm{~km}^{3}$ CVV ECWCS, maximum surface elevations are less than $2 \mathrm{~m}$ along 
the coast. A more detailed analysis of energy dissipation over the wide shelf indicated that it is essentially due to bottom friction, with wave breaking being only locally important, and hence the tsunami coastal inundation and impact would be sensitive to the value of the bottom friction coefficient; here, we used a uniformly low value, corresponding to coarse sand, which should ensure conservative results. More analyses regarding this aspect will be left out for future work.

For both CVV scenarios, we observe a significant alongshore modulation of these maximum surface elevations, following a closely similar pattern. This results in part from the source directionality, but more importantly from bathymetric wave focusing and de-focusing effects over the wide continental shelf, which become most important nearshore, in shallower water. The controlling effect of the continental shelf on the alongshore pattern of surface elevations is confirmed by performing a simplified ray-tracing analysis. As a corollary, this control implies that the long waves of any tsunami will essentially refract in a similar way to shore, whatever their initial angle of incidence. Here, this means that tsunamis generated from different CVV flank collapse mechanisms and volumes should focus their impact on the USEC in a similar manner, with areas of enhanced coastal tsunami hazard being in large part independent from details of the initial tsunami source.

Additional simulations in regional grids show that, along the western European and African coasts, the impact from both CVV scenarios would be much larger than on the USEC, because of the proximity to La Palma. For the smaller $80 \mathrm{~km}^{3}$ source, results indicate that, after 1h30', western Sahara and NW Morocco would be impacted by over $10 \mathrm{~m}$ surface elevations and, $2 \mathrm{~h} 30$ ' to $3 \mathrm{~h}$ into the event, the areas of Lisbon and Coimbra in Portugal would face over $5 \mathrm{~m}$ surface elevations. Similar to the USEC, the coastal impact from the most extreme CVV source would be even more dire.

Tsunami coastal impacts mentioned above, however, were computed in the still rather coarse regional grids, (with 15-20 arc-sec resolution), and more accurate and detailed inundation simulations must be conducted in finer nested grids to accurately assess site specific coastal tsunami hazard for the most impacted, exposed, or vulnerable areas. Such detailed inundation mapping is underway for the USEC, under the auspices of the US NTHMP and, in this paper, we show one example of a high-resolution tsunami inundation map computed for Ocean City (MD), based on the most extreme CVV flank collapse scenario; in this low laying area, we find that the extent of inundation and tsunami penetration would be very large. Other maps are currently being prepared for similarly highly impacted areas, based on these CVV flank collapse scenarios and other relevant extreme tsunami sources in the 
Atlantic Ocean Basin. Such maps can be used to mitigate the impact of future large tsunamis, through appropriate coastal development, and education and training of the populations regarding evacuation routes and sites.

\section{Acknowledgements}

Partial funding for this work was provided by grant \#NA10NMS4670010 of the National Tsunami Hazards Mitigation Program (NTHMP), grant \#EAR-09-11499 of the US National Science Foundation, and grant \#037058 of the European Commission.

\section{References}

Abadie S., Caltagirone J.P. and P. Watremez, Splash-up generation in a plunging breaker. Comptes Rendus de l'Académie des Sciences, Ser. IIB, 326:553559, 1998.

Abadie S., Morichon D., Grilli S.T. and S. Glockner, Splash-up generation in a plunging breaker. La Houille Blanche, 1 (Feb. 2008):21-26, doi:10.1051/lhb:2008001, 2008.

Abadie S., Morichon D., Grilli S.T. and S. Glockner, Numerical simulation of waves generated by landslides using a multiple-fluid Navier-Stokes model. Coastal Engineering, 57:779-794, doi:10.1016/j.coastaleng.2010.03.003, 2010.

Abadie S., Harris J.C., Grilli S.T. and R. Fabre, Numerical modeling of tsunami waves generated by the flank collapse of the Cumbre Vieja Volcano (La Palma, Canary Islands) : tsunami source and near field effects. Journal of Geophysical Research, 117:C05030, doi:10.1029/2011JC007646, 2012.

Barkan, R., ten Brick, U.S. and Lin, J. Far field tsunami simulations of the 1755 Lisbon earthquake:Implication for tsunami hazard to the U.S. East Coast and the Caribbean. Marine Geology, 264:109-122, 2009.

Bouws, E., and J. A. Battjes, A Monte Carlo approach to the computation of refraction of water waves. Journal of Geophysical Research: Oceans, 87(C8): 5718-5722, 1982.

Carracedo J., Day S., Guillo, H. and P. Gravestock, Later stage of volcanic evolution of La Palma, Canary Islands: rift evolution, giant landslides, and the genesis of the Caldera de Taburiente. Bulletin of the Geological Society of America, 111:755-768, 1999.

Cochonat P., Lenat J. F., Bachelery P., Boivin P., Corniglia B., Deniel C., Labazuy P., Lipman P., Oilier G., Savoye B., Vincent P. and M. Voisset, Importance des dépôts gravitaires dans la mise en place d'un système volcano-sédimentaire sous-marin (Volcan de la Fournaise, Ile de la Réunion). Comptes Rendus de l' Académie des Sciences, Ser. IIB., 311:679-686, 1990.

Days S.J., Watts P., Grilli S.T. and J.T. Kirby, Mechanical models of the 1975 Kalapana, Hawaii earthquake and tsunami. Marine Geology, 215:59-92, 2005.

Dean, R. G., and Dalrymple, R. A. Water wave mechanics for engineers and scientists. World Scientific, Advanced Series on Ocean Engineering, Prentice-Hall, 1991. 
Fritz, H.M. and J.C. Borrero. Somalia field survey of the 2004 Indian Ocean Tsunami. Earthquake Spectra 22(S3):S219-S233, 2006.

Geist E., P. Lynett, and J. Chaytor, Hydrodynamic modeling of tsunamis from the Currituck landslide. Marine Geology, 264:41-52, 2009.

Gisler G., Weaver R. and M. Gittings, SAGE calculations of the tsunami threat from La Palma. Science of Tsunami Hazards, 24:288-301, 2006.

Glimsdal S., Pedersen G.K., Harbitz C.B., and Løvholt F., Dispersion of tsunamis: does it really matter ? Nat. Hazards Earth Syst. Sci., 13:1507-1526, doi:10.5194/nhess-13-1507-2013, 2013.

Grilli, A.R., Grilli S.T., David, E. and C. Coulet. Modeling of tsunami propagation in the Atlantic Ocean Basin for tsunami hazard assessment along the North Shore of Hispaniola. In Proc. 25th Offshore and Polar Engng. Conf. (ISOPE15, Kona, HI, USA. June 21-26, 2015). Intl. Society of Offshore and Polar Engng., 8 pps., 2015a.

Grilli S.T., Dubosq S., Pophet N., Pérignon Y., Kirby J.T., and F. Shi, Numerical simulation and first-order hazard analysis of large co-seismic tsunamis generated in the Puerto Rico thrench: near-field impact on the North shore of Puerto Rico and far-field impact on the US East Coast. Natural Hazards and Earth System Sciences, dpi:10:2109-2125, 2010.

Grilli, S.T., Harris, J., F. Shi, J.T. Kirby, T.S. Tajalli Bakhsh, E. Estibals and B. Tehranirad, Numerical modeling of coastal tsunami dissipation and impact. In Proc. 33rd Intl. Coastal Engng. Conf. (P. Lynett and J. Mc Kee Smith, eds.) (ICCE12, Santander, Spain, July, 2012), 12 pps. World Scientific Publishing Co. Pte, 2012.

Grilli, S.T., J.C. Harris, T. Tajali-Bakhsh, T.L. Masterlark, C. Kyriakopoulos, J.T. Kirby and F. Shi, Numerical simulation of the 2011 Tohoku tsunami based on a new transient FEM co-seismic source: Comparison to far- and near-field observations. Pure and Applied Geophysics, 170:1333-1359, doi:10.1007/s00024012-0528-y, 2013.

Grilli S.T., O’Reilly C., Harris J.C., Tajalli-Bakhsh T., Tehranirad B., Banihashemi S., Kirby J.T., Baxter C.D.P., Eggeling T., Ma G. and F. Shi, Modeling of SMF tsunami hazard along the upper US East Coast: Detailed impact around Ocean City, MD. Natural Hazards, 76(2):705-746, doi: 10.1007/s11069-014-15228, 2015b.

Grilli, S.T., Taylor, O.-D. S., Baxter, D.P. and S. Maretzki, Probabilistic approach for determining submarine landslide tsunami hazard along the upper East Coast of the United States. Marine Geology, 264(1-2):74-97, doi:10.1016/j.margeo.2009.02.010, 2009.

Grilli S.T., Ioualalen M., Asavanant J., Shi F., Kirby J.T., and P. Watts, Source constraints and model simulation of the December 26, 2004 Indian Ocean tsunami. Journal of Waterway, Port, Coastal, and Ocean Engineering, 33:414-428, 2007.

Grilli, S.T. and P. Watts. Tsunami generation by submarine mass failure Part I : Modeling, experimental validation, and sensitivity analysis. J. Waterway Port Coastal and Ocean Engng., 131(6):283-297, 2005.

Hirt C.W. and B.D. Nichols, Volume of fluid (VOF) method for the dynamics of free boundaries. Journal of Computational Physics, 39:201-225, 1981.

Holcomb R. T. and R.C. Searle, Large landslides from oceanic volcanoes. Marine Geotechnology, 10:19-32, 1991.

Hunt J.E., Wynn R.B., Masson D.G., Talling P.J., and D.A.H. Teagle, Sedimentological and geochemical evidence for multistage failure of volcanic island landslides: 
A case study from Icod landslide on north Tenerife, Canary Islands. Geochem. Geophys. Geosyst., 12(12), 2011.

Hunt J.E., Wynn R.B., Talling P.J. and D.G. Masson, Multistage collapse of eight western Canary Island landslides in the last 1.5 Ma: Sedimentological and geochemical evidence from subunits in submarine flow deposits. Geochem. Geophys. Geosyst., 14(7):1525-2027, 2013.

Inoue K., Shimabara-Shigatusaku Earthquake and topographic changes by Shimabara Catastrophe in 1792. Geographical Reports Tokyo Metropolitan University, 35:59-69, 2000.

Ioualalen M., Asavanant J., Kaewbanjak N., Grilli S.T., Kirby J.T. and P. Watts, Modeling the 26th December 2004 Indian Ocean tsunami: Case study of impact in Thailand. Journal of Geophysical Research, 112:C07024, doi:10.1029/2006JC003850, 2007.

Kaiser G., Scheele L., Kortenhaus A., Lvholt F., Rmer H., and Leschka S., The influence of land cover roughness on the results of high resolution tsunami inundation modeling, Nat. Hazards Earth Syst. Sci., 11:2521-2540, doi:10.5194/nhess-112521-2011, 2011.

Karlsson J.M., Skelton A., Sanden M., Ioualalen M., Kaewbanjak N., Pophet N., Asavanant, J. and A. von Matern, Reconstructions of the coastal impact of the 2004 Indian Ocean tsunami in the Khao Lak area, Thailand. Journal of Geophysical Research, 114:C10023, 2009.

Kirby J.T., Shi F., Tehranirad B., Harris J.C. and S.T. Grilli, Dispersive tsunami waves in the ocean: Model equations and sensitivity to dispersion and Coriolis effects. Ocean Modeling, 62:39-55, doi:10.1016/j.ocemod.2012.11.009, 2013.

Legros, F., The mobility of long-runout landslides. Engineering Geology, 63:301-331, 2002.

Løvholt F., Pedersen G. and G. Gisler, Oceanic propagation of a potential tsunami from the La Palma Island. Journal of Geophysical Research, 113:C09026, 2008.

Lubin P., Vincent S., Abadie S. and J.P. Caltagirone, Three-dimensional large eddy simulation of air entrainment under plunging breaking waves. Coastal Engineering, 53:631-655, 2006.

Mader C.L., Modeling the La Palma landslide tsunami. Science of Tsunami Hazards., 19:150-170, 2001.

Madsen P.A., D.R. Fuhrman and H. A. Schaffer, On the solitary wave paradigm for tsunamis. J. Geophys. Res., 113:C12012, 2008.

Masson D., Watts A., Gee M., Urgeles R., Mitchell N., Bas T.L. and M. Canals, Slope failures on the flanks of the western Canary Islands. Earth-Science Review, $57: 1-35,2002$.

Mohammed, F. and Fritz, H.M. Physical modeling of tsunamis generated by three-dimensional deformable granular landslides. J. Geophys. Res. Oceans, 117:C11015, 2012.

Moore J.G., Clague D.A., Holcomb R.T., Lipman P.W., Normark W.R. and M.E. Torresan, Prodigious submarine landslides on the Hawaiian Ridge. Journal of Geophysical Research, 94:17465-17484, 1989.

Morichon D. and S. Abadie, Vague générée par un glissement de terrain, influence de la forme initiale et de la loi de déformabilité du glissement. La Houille Blanche, 1:111-117, 2010.

Oehler J.F., Labazuy P. and J.F. Lénat, Recurrence of major flank landslides during the last $2 \mathrm{Ma}$ history of Réunion Island. Bulletin Volcanology, 66:585-595, 2004. 
Pararas-Carayannis G., Evaluation of the threat of mega tsunamis generation from postulated massive slope failures of island stratovolcanoes on La Palma, Canary Islands, and on the island of Hawaii. Science of Tsunami Hazards, 20:251, 2002.

Pérignon Y., Tsunami hazard modeling. Master's thesis, University of Rhode Island and Ecole Centrale de Nantes, 2006.

Riss J., Tric E., Fabre R., Lebourg T. and S. Abadie, Potential collapse of the Cumbre Viejas volcanic edifice (Canary Island, Spain). Geophys. Res. Abstr., 12, EGU2010-4843, EGU General Assembly, 2010.

Robinson J.E. and B.W. Eakins, Calculated volumes of individual shield volcanos at the young end of the Hawaiian Ridge. Volcanologic Geothermal Research, 151:309-317, 2006.

Ryan W.B.F., Carbotte S.M., Coplan J.O., O’Hara S., Melkonian A., Arko R., Weissel A., Ferrini V., Goodwillie A., Nitsche F., Bonczkowski J. and R. Zemsky, Global Multi-Resolution Topography synthesis. Geochemistry Geophysics Geosystems, 10:Q03014, 2009.

Shi F., Kirby J.T., Harris J.C., Geiman J.D., and S.T. Grilli, A high-order adaptive time-stepping TVD solver for Boussinesq modeling of breaking waves and coastal inundation. Ocean Modelling, 43-44:36-51, 2012.

Tappin D.R., Watts P. and S.T. Grilli, The Papua New Guinea tsunami of 1998: anatomy of a catastrophic event. Natural Hazards and Earth System Sciences, 8:243-266, 2008.

Tappin D.R., Grilli S.T., Harris J.C., Geller R.J., Masterlark T., Kirby J.T., F. Shi, G. Ma, K.K.S. Thingbaijamg, and P.M. Maig, Did a submarine landslide contribute to the 2011 Tohoku tsunami ?, Marine Geology, 357:344-361 doi: 10.1016/j.margeo.2014.09.043, 2014.

Tehranirad B., Shi F., Kirby, J.T., Harris J.C. and S.T. Grilli, Tsunami benchmark results for fully nonlinear Boussinesq wave model FUNWAVE-TVD, Version 1.0. Technical report, No. CACR-11-02, Center for Applied Coastal Research, University of Delaware, 2011.

ten Brink U.S., Chaytor J.D., Geist E.L., Brothers D.S. and B.D. Andrews, Assessment of tsunami hazard to the U.S. Atlantic margin. Marine Geology, 353:31-54, 2014.

Tinti S., Manucci A., Pagnoni G., Armigliato A. and F. Zaniboni, The 30th December 2002 landslide-induced tsunami in Stromboli: sequence of the events reconstructed from eyewitness accounts. Natural Hazards Earth System Science, 5:763-775, 2005.

Ward S. N. and S. Day, Cumbre Vieja Volcano potential collapse at La Palma, Canary Islands. Geophysical Research Letter, 28:397-400, 2001.

Watts P., Grilli S.T., Kirby J.T., Fryer G.J. and D.R. Tappin, Landslide tsunami case studies using a Boussinesq model and a fully nonlinear tsunami generation model. Natural Hazards and Earth System Sciences, 3:391-402, 2003.

Wei G., Kirby J.T., Grilli S.T. and R. Subramanya, A fully nonlinear Boussinesq model for free surface waves. Part I: Highly nonlinear unsteady waves. Journal of Fluid Mechanics, 294:71-92, 1995.

Wynn R. and D. Masson, Canary Islands landslides and tsunami generation: Can we use turbidite deposits to interpret landslide processes. In: Locat J, Mienert J (eds) Submarine Mass Movements and Their Consequences, 325- 332. Kluwer Academic Publishers Dordrecht Netherlands, 2003.

Zhou H., Moore C.W., Wei Y. and V.V. Titov, A nested-grid Boussinesq type approach to modelling dispersive propagation and runup of landslide generated tsunamis. Natural Hazards and Earth System Sciences, 11:2677-2697, 2011. 